\title{
A Review of Recent Changes in Southern Ocean Sea Ice, their Drivers and Forcings
}

\author{
William R. Hobbs*1,2, Rob Massom¹,3, Sharon Stammerjohn4, Phillip Reid ${ }^{1,5}$, Guy \\ Williams $^{6}$ and Walter Meier ${ }^{7}$
}

*Corresponding author

${ }^{1}$ Antarctic Climate and Ecosystems Cooperative Research Centre, Private Bag 80, University of Tasmania, Hobart, Tasmania 7001, Australia. whobbs@utas.edu.au

${ }^{2}$ ARC Centre of Excellence for Climate System Science, IMAS, Private Bag 129, University of Tasmania, Hobart, Tasmania 7001, Australia.

${ }^{3}$ Australian Antarctic Division, 203 Channel Highway, Kingston, Tasmania 7050, Australia.

${ }^{4}$ Institute of Arctic and Alpine Research, University of Colorado at Boulder, Boulder, CO, USA

${ }^{5}$ Australian Bureau of Meteorology, Centre for Australian Weather and Climate Research, Hobart, Tasmania, Australia

6 Institute for Marine and Antarctic Studies, Private Bag 129, University of Tasmania, Hobart, Tasmania 7001, Australia

${ }^{7}$ NASA Goddard Space Flight Center, Greenbelt, MD, USA

\begin{abstract}
Over the past 37 years, satellite records show an increase in Antarctic sea ice cover that is most pronounced in the period of sea ice growth. This trend is dominated by increased sea ice coverage in the western Ross Sea, and is mitigated by a strong decrease in the Bellingshausen and Amundsen seas. The trends in sea ice areal coverage are accompanied by related trends in yearly duration. These changes have implications for ecosystems, as well as global and regional climate. In this review, we summarise the research to date on observing these trends, identifying their drivers, and assessing the role of anthropogenic climate change. Whilst the atmosphere is thought to be the primary driver, the ocean is also essential in explaining the seasonality of the trend patterns.

Detecting an anthropogenic signal in Antarctic sea ice is particularly challenging for a number of reasons: the expected response is small compared to the very high natural variability of the system; the observational record is relatively short; and the ability of global coupled climate models to faithfully represent the complex Antarctic climate system is in doubt.
\end{abstract}




\section{Introduction}

Over the last 37 years, since the advent of regular satellite passive microwave observations of sea ice, there has been a small but statisticallysignificant increase in overall Southern Ocean (SO) sea ice coverage (Cavalieri et al., 1999; Zwally et al., 2002; Comiso and Nishio, 2008; Parkinson and Cavalieri, 2012), with several record maximum annual sea ice extents occurring in recent years (Turner et al., 2013a; Reid et al., 2015). This is in contrast to the Arctic, where there has been a strong decline in sea ice over the same period (Cavalieri et al., 2003; Comiso and Nishio, 2008; Cavalieri and Parkinson, 2012; Vaughan et al., 2013; Simmonds, 2015), and at a first pass is counter-intuitive in the context of a warming planet. Furthermore, coupled climate models run with realistic estimates of external climate forcings generally simulate a decrease in Antarctic sea ice coverage over the late $20^{\text {th }}$ Century (Turner et al., 2013d; Shu et al., 2015).

Since sea ice occurs as a result of ocean-atmosphere exchanges of heat, freshwater and momentum, and therefore integrates elements of the ocean and atmosphere circulation, our understanding of the observed sea ice changes also reflects our level of understanding of the Antarctic climate system as a whole. This is demonstrated by the proven importance of sea ice biases in models. For example, sea ice biases contribute to large uncertainties in future predictions of precipitation changes over Antarctica (Agosta et al., 2015; Bracegirdle et al., 2015), an important component of ice sheet mass balance and therefore of sea level rise. Understanding these changes and their relationship to the broader 
issue of climate change is a significant and important scientific challenge (Kennicutt et al., 2015).

As well as being an indicator of ocean-atmosphere interactions, SO sea ice and its accumulated snow cover play a significant role in the global climate system. Changes in sea ice extent can shift the latitude of the mid-latitude storm track belt, with greater sea ice coverage driving a poleward migration of the jet (Kidston et al., 2011; Raphael et al., 2011). The SO is an important sink for anthropogenic carbon, and dominates the ocean uptake of excess heat trapped by carbon emissions, because it is a zone of upwelling deep water that is both cool and relatively low in carbon, and hence can readily absorb both at the surface (Orsi et al., 1999; Johnson, 2008; Marshall and Speer, 2012; Frolicher et al., 2015; Morrison et al., 2015). Most of this uptake is north of the sea ice zone, but further south sea ice regulates the rate at which this upwelled water reaches the surface or is returned to the deep ocean (Iudicone et al., 2008; Kirkman and Bitz, 2011; Ohshima et al., 2013; Delille et al., 2014).

In modulating the global ocean heat uptake, SO sea ice indirectly affects thermosteric sea level rise (i.e. sea level rise due to thermal expansion of the ocean). It may also have an indirect impact on barystatic sea level change (i.e. sea level increase due to freshwater input into the ocean). Ice sheet discharge is buttressed in many locations by floating ice shelves, and can accelerate rapidly in the event of an ice shelf collapse (Scambos et al., 2004; Dupont and Alley, 2005). In turn, in certain locations ice shelves and outlet glaciers are mechanically coupled to fast ice (i.e. sea ice that is fixed to features of the icescape, such as land or grounded icebergs), suggesting that fast ice loss could affect the stability of ice shelves and outlet glaciers, hence also the Antarctic Ice Sheet coastal 
margins and outlet glaciers (Massom et al., 2010). Thermodynamically, sea ice processes may have a role in modulating the exposure of Antarctic ice shelves to warm circumpolar deepwater (Holland et al., 2010; St-Laurent et al., 2015), and in changing the temperature and salinity properties of that water which may also affect basal melt (Dutrieux et al., 2014). Additionally, changes in sea ice extent (SIE) may affect the surface mass balance of the Antarctic ice sheets, by increasing or decreasing the distance of the ice sheet from marine-source moisture, with a consequent change in snow accumulation on the ice sheet (Weatherly, 2004; Krinner et al., 2007).

Sea ice also plays a crucially important role in the structure and function of high-latitude SO ecosystems (Thomas and Dieckmann, 2009) and biogeochemical processes (Delille et al., 2014). Changes in SIE and the timing of ice-edge advance/retreat are thought to affect krill biomass (Ross et al., 2008; Steinberg et al., 2015), with potential impacts for krill-dependent fauna at higher trophic levels (e.g., whales, seals and penguins) (Massom and Stammerjohn, 2010; Ducklow et al., 2012; Constable et al., 2014; Saba et al., 2014). Regional changes in the sea ice cover have impacted the distribution of penguin species, with sea ice-obligate Adélie penguins being replaced by ice-tolerant gentoo and chinstrap penguins in the western Antarctic Peninsula where sea ice is in strong decline (McClintock et al., 2008; Massom and Stammerjohn, 2010; Ducklow et al., 2013).

In this article, we provide a substantive review of research to date into the observed changes in SO sea ice, and their causes. In section 2, we describe the magnitude, distribution and seasonality of the trends, and discuss uncertainties in the observations. In section 3, we discuss the coupled atmosphere, ocean and 
cryosphere processes that may explain the observed trends. In section 4 , we review the evidence of anthropogenic forcing in the observed trends.

\section{Measurements of sea ice change}

A number of metrics are used to describe the local and large-scale timevarying sea ice cover. Here we describe changes in each observed metric separately.

\subsection{Sea ice concentration}

Sea ice concentration (SIC) is a pixel/grid-scale observation defined as the fraction of ocean area that is covered by sea ice. It is the core sea ice observation derived from satellite passive microwave data from which most other metrics are derived. The spatial and seasonal SIC trends are plotted in Figure 1, based on the NASA Goddard-merged parameter in the NOAA/NSIDC Climate Data Record (CDR) product (Meier et al., 2013b), described in more detail below. During the austral summer and autumn (Figure $1 \mathrm{a}$ and $\mathrm{b}$ ), the largest trends are positive in the Weddell and western Ross Sea and negative in the Amundsen and Bellingshausen seas (ABS) (Liu et al., 2004; Holland, 2014), the latter especially along the western coast of the Antarctic Peninsula. In winter and spring (Figures 1c and d), the statistically significant trends are much less widespread and occur largely near the ice edge of the Ross Sea, with a reduction in the Bellingshausen Sea along the western coast of the Antarctic Peninsula (Figure 1c). East Antarctica has increased coastal sea ice in autumn and winter (Figures $1 b$ and d), and within the consolidated pack in spring (Figure 1d). King Hakon VII Sea has increased coverage in autumn and winter (Figures $1 \mathrm{~b}$ and $c$ ). 
a) Summer (DJF)

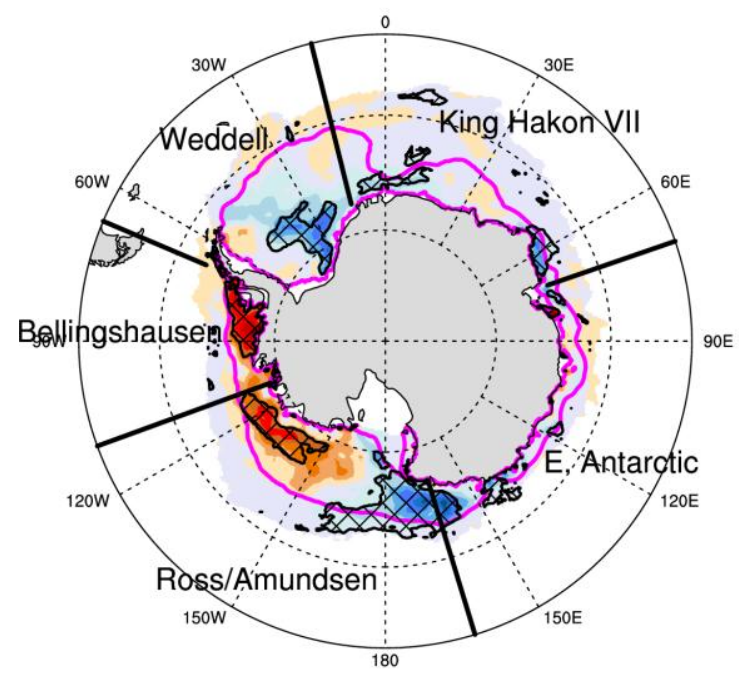

c) Winter (JJA)
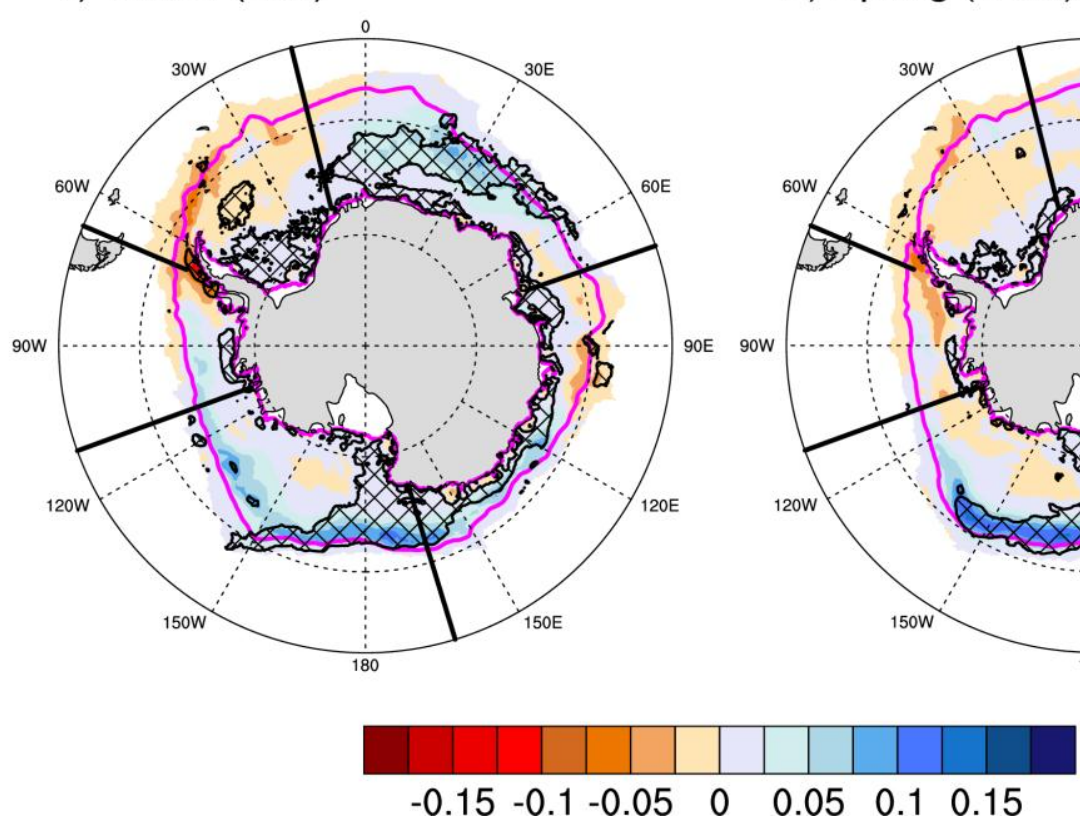

b) Autumn (MAM)

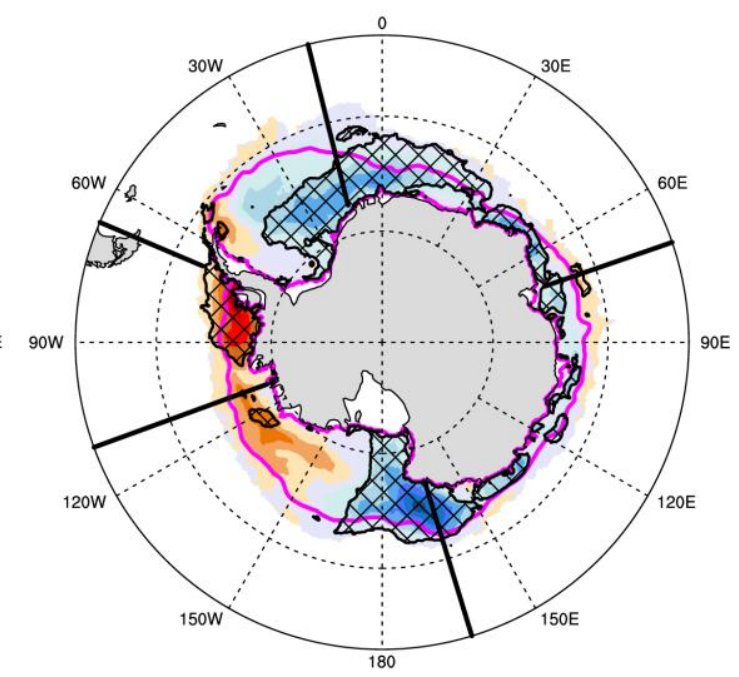

d) Spring (SON)

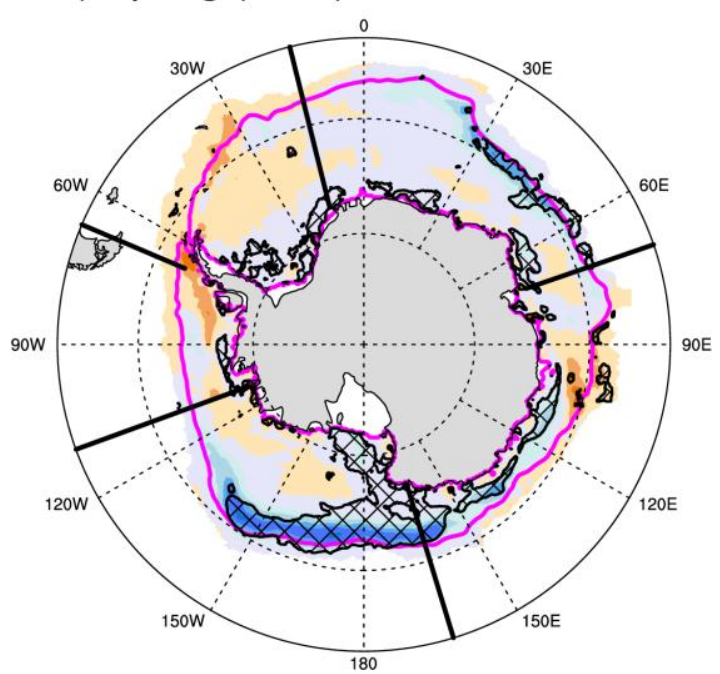

Figure 1-1979-2014 SIC trends (fraction/decade) by season. Data are from the NOAA/NSIDC Goddard-merged CDR monthly mean SIC product (Meier et al., 2013b). Magenta line shows the climatological mean 15\% SIC isoline, and hatching shows trends that are significant at the 95\% level. Sector boundaries shown in panel a) are as defined by Raphael and Hobbs (2014).

\subsection{Sea ice extent and area}

Sea ice change and variability are often described in terms of sea ice extent (SIE), which is the total area of sea ice coverage with a SIC greater than some threshold value (typically 15\%). SIE can be calculated over a range of 
domains: the total circumpolar region, specific sectors (such as those indicated in Figure 1a), or as a continuous function of longitude (Figure 2). Sea ice area (SIA) is a similar but less widely used metric, calculated as the total area of ice coverage for a given domain i.e., $\Sigma \operatorname{SIC}(\mathrm{x}, \mathrm{y}) \times \mathrm{A}(\mathrm{x}, \mathrm{y})$, where $\mathrm{A}$ is the area of each grid cell (e.g., Comiso and Nishio, 2008). These metrics are subtly different, because SIA excludes regions of open water within the ice pack, whereas SIE just gives the area defined by the land and ice edge and includes grid cells within the pack with SIC $<15 \%$ (e.g. polynyas). In practice the two metrics are highly correlated, but SIE is more commonly cited because uncertainties in passive microwave retrievals have less effect on SIE. 
a) Trend $\left(10^{2} \mathrm{~km}^{2} \mathrm{a}^{-1}\right)$

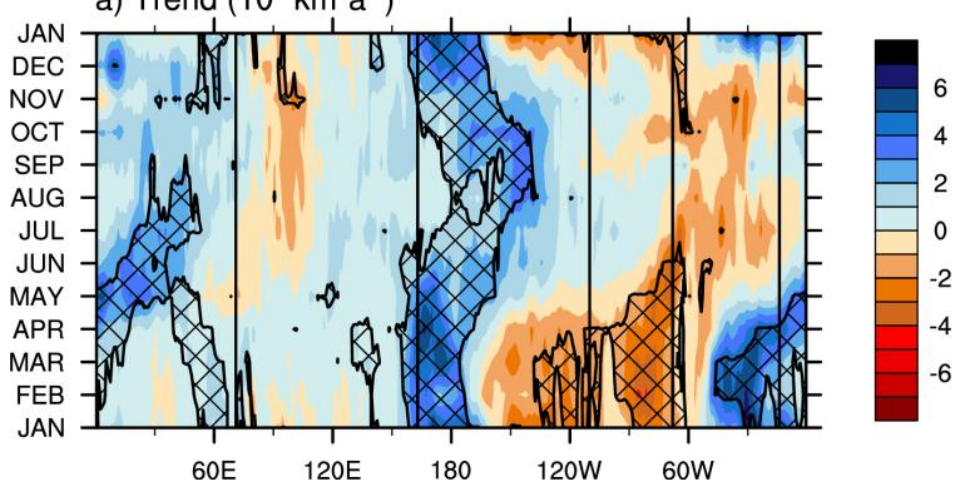

b) Trend/mean $\left(\% \mathrm{a}^{-1}\right)$

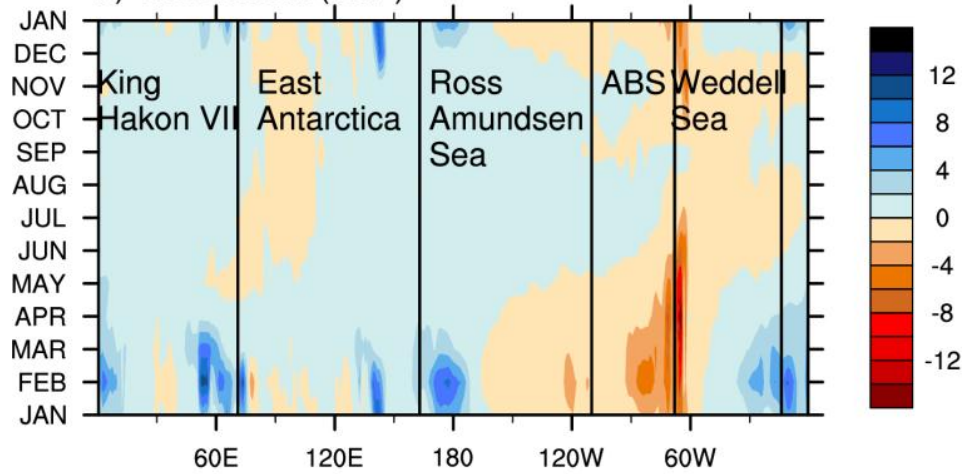

c) Trend/standard deviation $\left(\% \mathrm{a}^{-1}\right)$

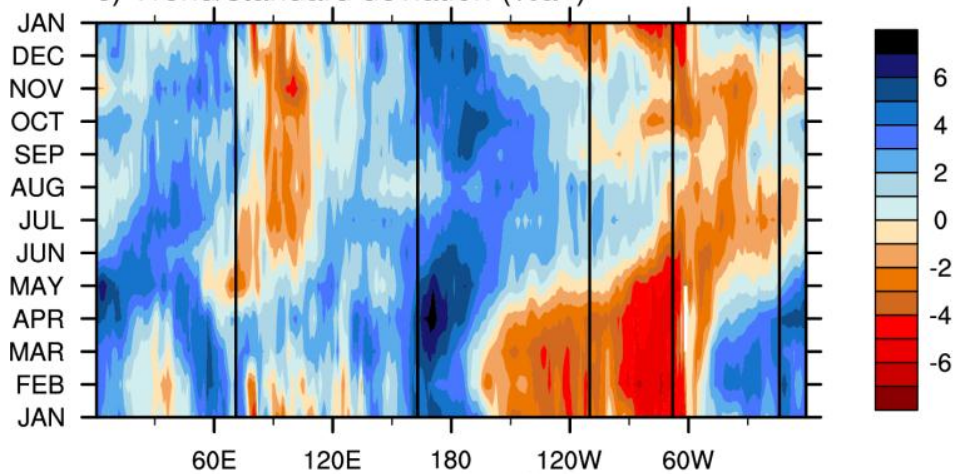

d) Standard deviation $\left(10^{2} \mathrm{~km}^{2}\right)$

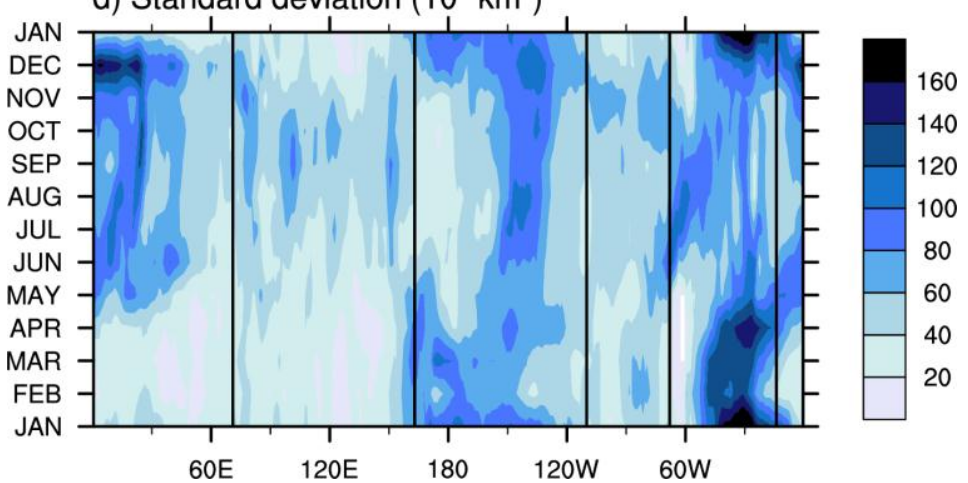

Figure 2: Metrics of 1979-2014 SIE change derived from the NOAA/NSIDC Goddard-merged CDR monthly SIC dataset, as a function of longitude and month. Vertical lines denote the different sectors shown in Figure 1. a) Trend $\left(10^{2} \mathrm{~km}^{2} \mathrm{a}^{-1}\right)$, with hatching showing trends that are significant at the 95\% level; b) Trend as a percentage of the climatological mean SIE; c) Trend as a percentage of the climatological standard deviation; and d) Standard deviation $\left(10^{2} \mathrm{~km}^{2}\right)$. 
The patterns of SIE trend and variability are shown in Figure 2. The SIE trend pattern largely agrees with the SIC trends shown in Figure 1, with large increased SIE in the Ross Sea in the warmer months (i.e. December-April) opposed by decreases in the ABS. Trends in the colder months (i.e. June-October) are generally weaker, and are only statistically significant in the Ross Sea. The sector boundaries shown in Figures 1 and 2 are based on SIE interannual variability (Raphael and Hobbs, 2014), but the trend patterns do not correspond well to these sector definitions. Furthermore, there is a positive interannual covariability between the Ross and western Amundsen Seas (Raphael and Hobbs, 2014), but the advance season trends for these sectors are opposite in sign. This suggests that the drivers of the West Antarctic trends are different from the usual modes of interannual variability.

Comparing the observed trends to the climatological mean of each location and month (Figure 2b) further highlights that the trend signals are most intense during the summer months. Figure $2 \mathrm{c}$ shows the ratio of the trends to the climatological standard deviations, a simple metric for the signal-to-noise ratio. This is highest in the summer months and for the Ross and ABS sectors, as reflected in the statistical significances in Figure 2a. Interestingly, there is some evidence of an eastward propagation of trends across the sectors from April to July, which even crosses the physical barrier of the Antarctic Peninsula $\left(60^{\circ} \mathrm{W}\right)$. The rate of propagation is similar to the $36-45^{\circ} /$ year of the atmosphere-ocean coupled Antarctic Circumpolar Wave (ACW: White and Peterson, 1996), although we note that subsequent studies show that the ACW is intermittent and not strictly circumpolar (Park et al., 2004), and the signal in Figure 2 may not be consistent across the length of the analysis period. We also note that in the Ross 
Sea there is westward trend propagation from September to December, which is not consistent with a continually eastward-moving ACW.

It is important to consider the limitations of the satellite data from which these trends are derived. The long-term record relies on cloud-penetrating passive microwave retrievals, which allow twice-daily or shorter temporal resolution throughout the year (essential for studies of sea ice duration - see section 2.3 below), but places a limit on the spatial resolution to about 12.5 25km (Cavalieri et al., 1999; Lubin and Massom, 2006), so that fine scale features such as leads and floes are not resolved. Also, passive microwave retrievals underestimate SIC where the ice is thinner than $20 \mathrm{~cm}$ and/or has a wet surface (Cavalieri, 1994), which means that observations near the ice edge may not be as reliable as within the consolidated pack. Since the Antarctic sea ice edge is seldom distinct but rather can be diffuse across many tens of kilometres (Massom and Stammerjohn, 2010), especially during retreat (Worby and Comiso, 2004), there is a significant ice area which is not well observed by passive microwave. Atmospheric changes may have changed the width of this marginal ice zone (Ackley et al., 2003; Stroeve et al., 2016), with implications for SIE trend estimates.

For change detection, it is preferable that the observation record is not only accurate but also homogeneous over time. The passive microwave record from mid-1978 to the present spans a number of different instruments (Cavalieri et al., 1999; Screen, 2011), and overlap periods between new and old sensors can be quite short (as little as two weeks in one case) limiting the accuracy of the inter-calibration over the full seasonal cycle (Meier et al., 2011). There are also algorithm differences in SIC estimates, but to date there has been insufficient 
ground-truthing to determine the 'best' algorithm or to properly assess uncertainty in algorithm estimates (Ivanova et al., 2014; Ivanova et al., 2015). Studies have suggested that instrument and algorithm changes may have spuriously magnified SO sea ice trends, which is evident in disagreements between trend estimates using older versions (since updated) of different SIC retrieval algorithms (Screen, 2011; Eisenman et al., 2014). In Figure 3, we compare SIE trends derived from four products. The first three, produced at NASA Goddard Spaceflight Center, are: the NASA Team algorithm (Cavalieri et al., 1999), Bootstrap algorithm (Comiso and Nishio, 2008), and an earlier version of the Bootstrap (Comiso, 1986) that was analysed by Eisenman et al. (2014). The fourth time series is the Goddard-merged estimate in the NOAA/NSIDC CDR that is used in Figures 1 and 2. This is a merged dataset that combines the Goddard NASA Team and Bootstrap Version 2 concentration fields (Peng et al., 2013; Meier et al., 2014).

The trend biases are fairly consistent throughout the year, although differences between the algorithms are slightly greater during the summer months, when challenging conditions such as thin ice and surface water from flooding are most prevalent. The difference between Versions 1 and 2 of the Bootstrap data reported by Eisenman et al. (2014) is clear in the total circumpolar SIE (Figure 3f), with the Bootstrap V1 data showing a lower trend in all seasons compared to the other datasets. The later version of the data, however, agrees very well with the NASA Team algorithm retrievals, and the merged data (which is a blend of the Bootstrap and Team retrievals) essentially follow Bootstrap V2. The differences between older Bootstrap V1 and the other retrievals occur in the East Antarctic sector only (Figure 3b), and for all other 
sectors there is little discernable difference. Importantly, the differences between the retrievals are small compared to the statistical uncertainty of the trends.

This comparison demonstrates firstly that the most-up-to date versions of the retrievals are largely in agreement, and the spurious trend indicated by Eisenman et al. (2014) exists in the version 1 data only. Secondly, for monthly or seasonal trends the differences are small compared to statistical uncertainty, and the reported trends can be considered robust. However, researchers should be aware that for trends calculated using all 12 months in each year, the increased number of data points will reduce the statistical uncertainty but the biases, being constant across all seasons, will remain largely the same - hence the relative importance of the biases is greater. 

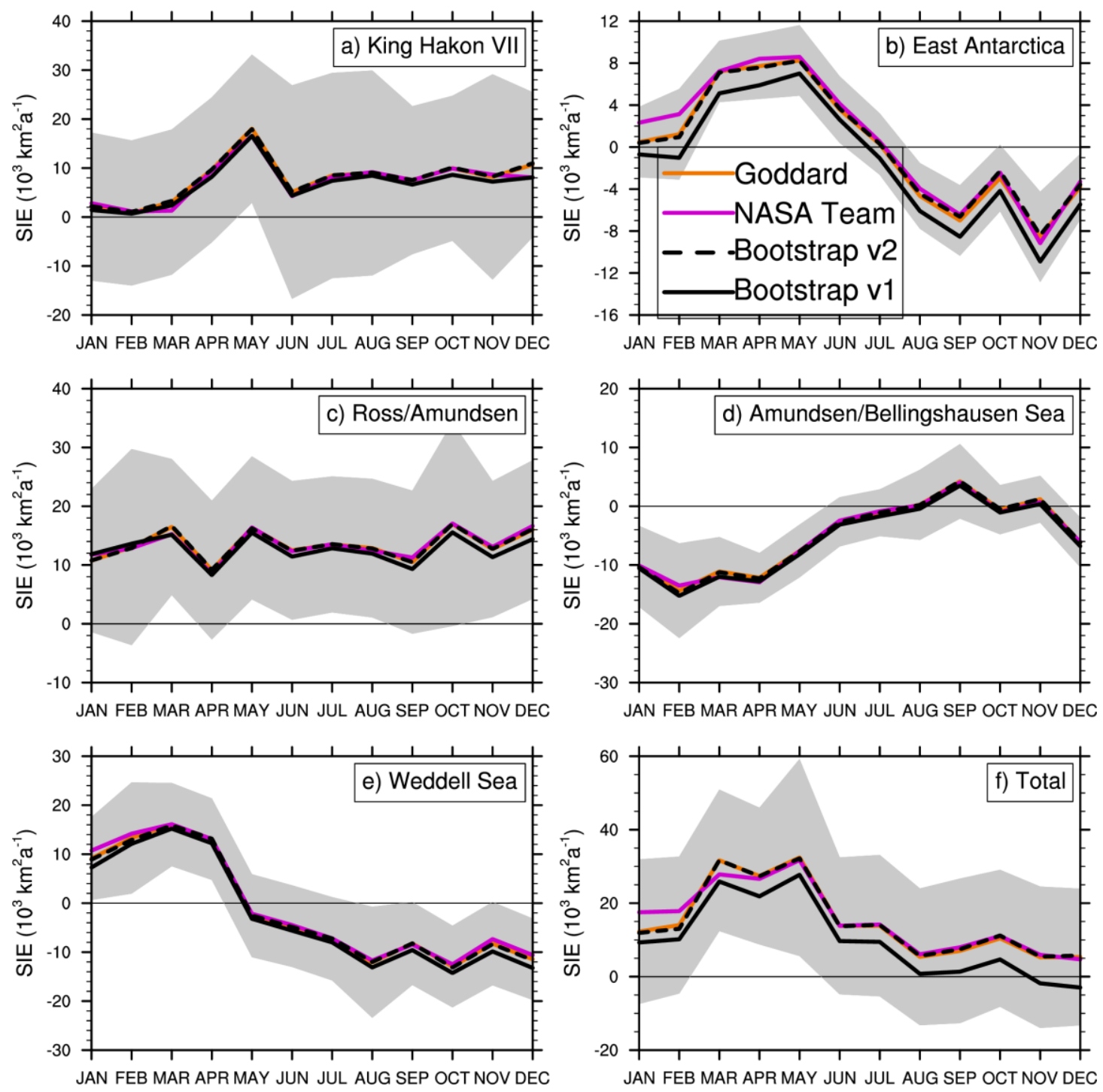

Figure 3: Comparison of 1979-2004 SIE trends by month ( $x$-axes) and sector (where sectors are as defined in Figure 1), using SIC estimated by Bootstrap Version 1, Bootstrap Version 2, NASA Team Version 2 and Goddard-merged. Grey shading shows the standard error of the Goddard-merged trend.

\subsection{Sea ice duration}

Sea ice duration represents the period in days per year that a location (pixel/grid square) is covered by sea ice. Change in ice coverage timing and duration has major implications for ecosystems (Massom and Stammerjohn, 2010) and ocean heating by insolation, with a possible feedback to subsequent ocean freezing (Stammerjohn et al., 2012). Parkinson (1994) first studied trends 
in SO sea ice duration, defining duration as the length of time that SIC was persistently above a given threshold (typically 15\%, as for SIE). The spatial pattern of trends in duration closely follow those of annual mean SIC (Parkinson, 1994; 2002; Stammerjohn et al., 2008; Stammerjohn et al., 2012), with sea ice duration in the Bellingshausen Sea shortening by 3.3 months between 1979 and 2011, and duration in the western Ross Sea increasing by 2.6 months.

In the western Ross Sea, the increased ice duration is due roughly equally to an earlier advance and later retreat, whilst in the Bellingshausen Sea the trend in later advance is about 1.5 times the trend towards earlier retreat (Table 1 , quoting trends from Stammerjohn et al., 2012). This seasonality is reflected in SIE trends (Figure 2a), where the Ross Sea trends occur throughout the year but the ABS SIE trends are concentrated in the advance season. Although we have focused on descriptions of the large-scale trends here, there are complex patterns of change in advance, retreat and duration within each sector (Massom et al., 2013; Stammerjohn et al., 2015).

Holland (2014) explored the role of autumn growth and spring melt in the seasonal dependence of SIC/SIE trends. He showed that in the ABS, an intensification of the spring melt leads to the observed summer decrease in SIC, consistent with earlier retreat in that region shown by Stammerjohn et al. (2012); a similar but reverse pattern emerges in the Ross Sea, where reduced spring melt leads to an increase in summer ice coverage. This is shown in Table 1, which shows the trends in timing and rate of sea ice expansion/contraction for the two regions. However, Holland (2014) also showed that these spring changes are offset by changes in the autumn freeze, leading to the lower SIC trends in winter. This seems at first glance to be inconsistent with Stammerjohn et al. 
(2012), who found that trends in both advance and retreat contributed to the trends in duration. These results can be reconciled by considering the rapidity of growth and melt. In the ABS, advance occurs later but is faster towards the end of the growth season, so that there is still an increase in freeze rate averaged over the growth season (Table 1, columns 4 and 5), hence the ice cover still recovers by the winter (Turner et al., 2013b). For the Ross Sea, there is an inverse corollary; ice advance is initially faster, but reduces towards the end of the autumn growth season. The reduction of the Ross Sea springtime melt rate is higher than reduced autumn growth rate, which is why, unlike other sectors, the Ross Sea has a significant SIE trend in all seasons.

\begin{tabular}{|c|c|c|c|c|}
\hline & \multicolumn{2}{|c|}{ Retreat } & \multicolumn{2}{|c|}{ Advance } \\
\hline & $\begin{array}{c}\text { Day of retreat } \\
\text { (days/a) }\end{array}$ & $\begin{array}{c}\text { SON } \\
\delta \text { SIE } / \delta t \\
\left(10^{3} \mathbf{k m}^{2} \mathbf{a}^{-}\right. \\
2)\end{array}$ & $\begin{array}{c}\text { Day of } \\
\text { advance } \\
\text { (days/a) }\end{array}$ & $\begin{array}{c}\text { MAM } \\
\delta \text { SIE } / \delta \mathbf{t} \\
\left(10^{3}\right. \\
\left.\mathbf{k m}^{2} \mathbf{a}^{-2}\right)\end{array}$ \\
\hline $\mathrm{ABS}$ & $\begin{array}{c}-1.2 \\
\text { (earlier) }\end{array}$ & $\begin{array}{c}-21.7 \\
\text { (higher } \\
\text { contraction) }\end{array}$ & $\begin{array}{c}+1.9 \\
\text { (later) }\end{array}$ & $\begin{array}{c}+17.1 \\
\text { (higher } \\
\text { expansion) }\end{array}$ \\
\hline Western Ross & $\begin{array}{l}+1.2 \\
\text { (later) }\end{array}$ & $\begin{array}{c}+30.5 \\
\text { (lower } \\
\text { contraction) }\end{array}$ & $\begin{array}{c}-1.3 \\
\text { (earlier) }\end{array}$ & $\begin{array}{c}-8.6 \\
\text { (lower } \\
\text { expansion) }\end{array}$ \\
\hline
\end{tabular}

Table 1 - Trends in the 1979-2011 timing of sea ice advance and retreat for Amundsen/Bellingshausen seas (260-296 ${ }^{\circ}$ E) and western Ross Sea (155-206 ${ }^{\circ}$ E), from (Stammerjohn et al., 2012), compared with trends in March-May (MAM) and September-November (SON) expansion rates (Holland, 2014) in the same spatial domains.

\subsection{Ice thickness/Volume}

Although SIC retrievals give invaluable information about the spatial cover of sea ice, to truly understand changes in SO sea ice we also need to consider the sea ice volume (Maksym et al., 2012), since it is through volume changes (i.e. sea ice production and melt) that sea ice has its greatest impact on the water column. Through brine rejection during the autumn freeze and 
freshening during the autumn melt, sea ice volume fluxes set both the salinity flux at the surface and the convective stability of the water column. Also, the northward transport of sea ice results in a net meridional freshwater flux that has physical and biological implications for the water column. Since more ice is created near the coast than is melted, shelf water remains very salty and dense, which is important for Antarctic Bottom Water (AABW) formation, whereas the amount of surface melt further north modulates the loss of heat from ocean to atmosphere there.

Unfortunately, reliable sea ice thickness (SIT) data in the Southern Hemisphere are restricted to in situ measurements from dedicated research stations (Haas et al., 2008), underway observations from icebreakers (Worby et al., 2008b), and most recently from autonomous underwater vehicles (Williams et al., 2015). The latter appears to show that the former approaches likely underestimate SIT. All of these data are temporally and spatially sparse (Giles et al., 2008), and serve primarily to demonstrate the high spatial variability of SIT over a variety of length scales. Therefore, routine estimation of large-scale SIT from space is an important area of research and a high priority.

In theory, large-scale repeat information on SIT can be derived from satellite altimeter measurement of the height of the ice or snow surface above the local sea surface, via the hydrostatic equilibrium relationship (Lubin and Massom, 2006; Kwok, 2010). In practice, however, conversion of satellite altimeter measurements to SIT is difficult due to: a) the relatively small freeboard of Antarctic sea ice compared to that in the Arctic (Maksym and Markus, 2008); and b) the need for independent knowledge (largely lacking) of coincident snow cover thickness and sea ice and snow density (e.g. Alexandrov 
et al., 2010). Satellite passive microwave-derived estimates of large-scale snow thickness tend to underestimate actual thickness (Worby et al., 2008a). Other complicating factors include difficulties in accurately quantifying precipitation and accumulation over sea ice (Maksym and Markus, 2008), and the strong redistribution of snow by wind (Leonard and Maksym, 2011) and extensive conversion of snow into sea ice (described further in section 3.1).

To overcome these issues, some studies adopt alternative approaches, such as using an empirical relationship between SIT and the total snow plus sea ice thickness above the ocean surface (Xie et al., 2013), or assuming that all height above the surface is snow depth (Kurtz and Markus, 2012). All show some success (when compared to field observations), but the strong spatial and seasonal dependence of snow cover, and snow and sea ice density, remain significant challenges in gaining a long-term record of SO sea ice volume (Kwok and Maksym, 2014).

Given the difficulties of SIT measurement/monitoring, a valid question is whether areal ice cover is a robust proxy of large scale changes in volume. The evidence is somewhat conflicted. On the one hand, observational studies show that variability in volume is predominately due to changes in SIE in the Ross (Comiso et al., 2011) and ABS sectors (Xie et al., 2013), and areal cover may be a good indicator of changes in volume. On the other hand, in some regions winddriven compaction events can cause an ice pack that has a small areal cover but is thickened by rafting and ridging, so that the true volume is masked by low SIE (Massom et al., 2006; Massom et al., 2008). Kurtz and Markus (2012) suggested that decreased ice coverage in most sectors in spring and summer could be counterbalanced by an increase in ice thickness. Sea ice-ocean models forced by 
realistic winds indicate that while SIT and SIC trends counteract each other in the Bellingshausen Sea, they complement each other's contributions to ice volume change in the Weddell, Ross and Amundsen Seas - showing a spatial dependence in this effect (Zhang, 2014).

Clearly, the lack of a reliable large-scale climate record of SIT remains a significant gap in our SO observations. Some progress has been made in recent years estimating time-varying SIT using data assimilation (Goosse et al., 2009; Massonnet et al., 2013; Holland et al., 2014; Zhang, 2014). These assimilations agree with observed climatologies of SIT, and agree with observed SIC trends to a varying degree; however, as we demonstrate in the next section with regard to well-established atmospheric reanalyses, the lack of reliable in-situ data for validation means that SIT is likely to remain highly uncertain for some time.

\subsection{Proxy and historical records of SIE}

A significant challenge in interpreting observed SIE changes is the shortness of the passive microwave record, which at less than 40 years cannot truly resolve multi-decadal variability and may not be representative of longterm trends (Goosse et al., 2009). Early NIMBUS satellites provide snapshot estimates of SIE as far back as 1964 (Meier et al., 2013a; Gallaher et al., 2014). At the time of writing, digitised data from NIMBUS 1 have been released for $20^{\text {th }}$ August - 19th September 1964, (Meier et al., 2013a), NIMBUS 2 for $16^{\text {th }}$ May $15^{\text {th }}$ August 1966, and NIMBUS 3 for $1^{\text {st }}$ October $1969-15^{\text {th }}$ January 1970 (Gallaher et al., 2014). While these data are invaluable, care must be taken in comparing them with modern records. First, the data are based on human judgements of the ice edge from poor-resolution visible images that are affected 
by cloud cover. This means that there may be a bias compared to satellite passive microwave-derived estimates, which is an important consideration for long-term change detection; this bias is yet to be quantified in the literature. Secondly, since they are snapshots over fairly short time periods (especially in the case of NIMBUS 1), internal variability is difficult to ascertain.

Bridging the gap between the early NIMBUS data and regular passive microwave monitoring is the US Navy-NOAA Joint Ice Center (JIC, now known as the U.S. National Ice Center [NIC]) dataset (Ropelewski, 1990; Dedrick et al., 2001). These are estimates of sea ice area from digitised weekly analysis charts from 1973-1990, and for the SO were based on infrequent ship data, and satellite data (Godin and Barnett, 1979), including where available passive microwave retrievals from NIMBUS 5 ESMR (Parkinson et al., 1999). There are some issues in using the JIC data for change detection, since the 'monthly means' are in fact based on the weekly mean at the end of each month, so that month-to-month variability is exaggerated (Ropelewski, 1990). These estimates also have uncertainties stemming from inhomogeneous data sources, and subjectivity in the choice of SIE by the original analysts (Cavalieri et al., 2003).

To go further back in time, proxies must be used to reconstruct sea ice change and variability, and a number of efforts have been made to extend the SIE record. One approach uses historical whaling records from the 1930s to the 1980s to estimate sea ice changes over the mid-20th Century (de la Mare, 1997; Cotte and Guinet, 2007; de la Mare, 2009), with the premise that since whaling fleets tended to favour the ice edge for both catch and processing, whale catch locations can be used as a proxy for ice edge location. These analyses suggested that there was zonal mean southward migration of the summer (October-March) 
ice edge of $2.41^{\circ}$ latitude in the $1970 \mathrm{~s}-1980 \mathrm{~s}$, compared to the $1930-1950 \mathrm{~s}$. This estimate has been challenged, on the basis of summer-time biases between ship and satellite estimates of ice edge location (Ackley et al., 2003).

King and Harangozo (1998) used coastal station temperature data to infer a southward migration of the west Antarctic Peninsula autumn and winter sea ice edge of approximately $1^{\circ}$ between the $1945-1954$ and $1973-1994$ periods, based on the strong coupling between local sea ice cover and air temperature. SIC in the Weddell Sea is strongly correlated with the 1903-2008 record of the onset and subsequent melt of fast ice at stations in two locations on the South Orkney Islands (Murphy et al., 1995; Murphy et al., 2014).

A number of ice core chemistry records have been used to reconstruct regional patterns of interannual SIE, including methane sulphonic acid or MSA (Curran et al., 2003; Abram et al., 2010) and excess-deuterium (Sinclair et al., 2014). MSA is empirically related to the maximum winter extent of the seasonal sea ice zone in certain regions, and MSA proxies indicate that maximum SIEs have declined since the mid $20^{\text {th }}$ Century in the East Antarctic sector (Curran et al., 2003) and the Bellingshausen Sea (Abram et al., 2010). The obvious limitation of MSA reconstructions is that the most intense recent trends have occurred in the warmer seasons. The excess-deuterium record from a Whitehall Glacier ice core is correlated with Ross SIE, and indicates that the current expansion there started in the mid-1960s (Sinclair et al., 2014); this seems to be confirmed by recent independent ice cores (Thomas and Abram, 2016).

Figure 4 synthesises the satellite estimates and reconstructions for sectors defined by the proxies used. Also shown is SIE from the monthly SIC HadISST v2.2 dataset (Titchner and Rayner, 2014). For the post -1973 period, 
this is largely a representation of the satellite record, but it uses two different climatologies based on ship data for the 1929-1939 and 1947-1962 periods, and interpolation for data-free periods. (Note that whaling records are not available for the winter, and as yet there is no other proxy for summer SIE.)

For the summer period both the whaling data and HadISST indicate a marked decrease in summer SIE since the 1960s in the Weddell, E. Antarctic and Ross seas that is large in magnitude compared to the satellite-era trends; there are limited records for the ABS region. The HadISST data may not be strictly independent of the whaling reconstruction. The 1929-1939 climatology used in HadISST includes sea ice observations from Norwegian and English whaling vessels (Deutsches Hydrographisches Institute, 1950), and the 1947-1962 climatology is based on various data sources, which may include observations from Soviet whaling expeditions also used by de la Mare (Titchner, H: personal communication). We note that the HadISST is biased high compared to the passive microwave record whilst the few whaling records that overlap with the satellite era are not, which highlights the challenge of comparing estimates from different data sources.

The winter reconstructions indicate modest reductions in SIE over the $20^{\text {th }}$ Century in the East Antarctic and ABS sectors. The Ross Sea reconstruction indicates that the current increase in SIE started in the 1960s, preceded by a pronounced decrease over the 1950s. The winter reconstructions do not, however, agree with the HadISST climatologies, which show a large decrease in winter SIE in most sectors (except the ABS) that is not supported by the proxies. Few observations constrain the pre-satellite winter climatologies used in the HadISST data (Titchner and Rayner, 2014), which therefore must be treated with 
some caution. In interpreting these results, the large uncertainty range of the reconstructions must also be borne in mind, as must the under-representation of multi-decadal variability inherent in linear reconstructions (von Storch et al., 2004). Whilst there is no objective way of assessing which of the pre-satellite records in Figure 4 is most reliable, we note that the winter decrease shown in the HadISST record seems implausibly large, and since a similar decrease is shown in summer, we would also question the reliability of the whaling reconstructions. Recent work using sea ice observations from early polar explorations supports this view (Edinburgh and Day, 2016). 

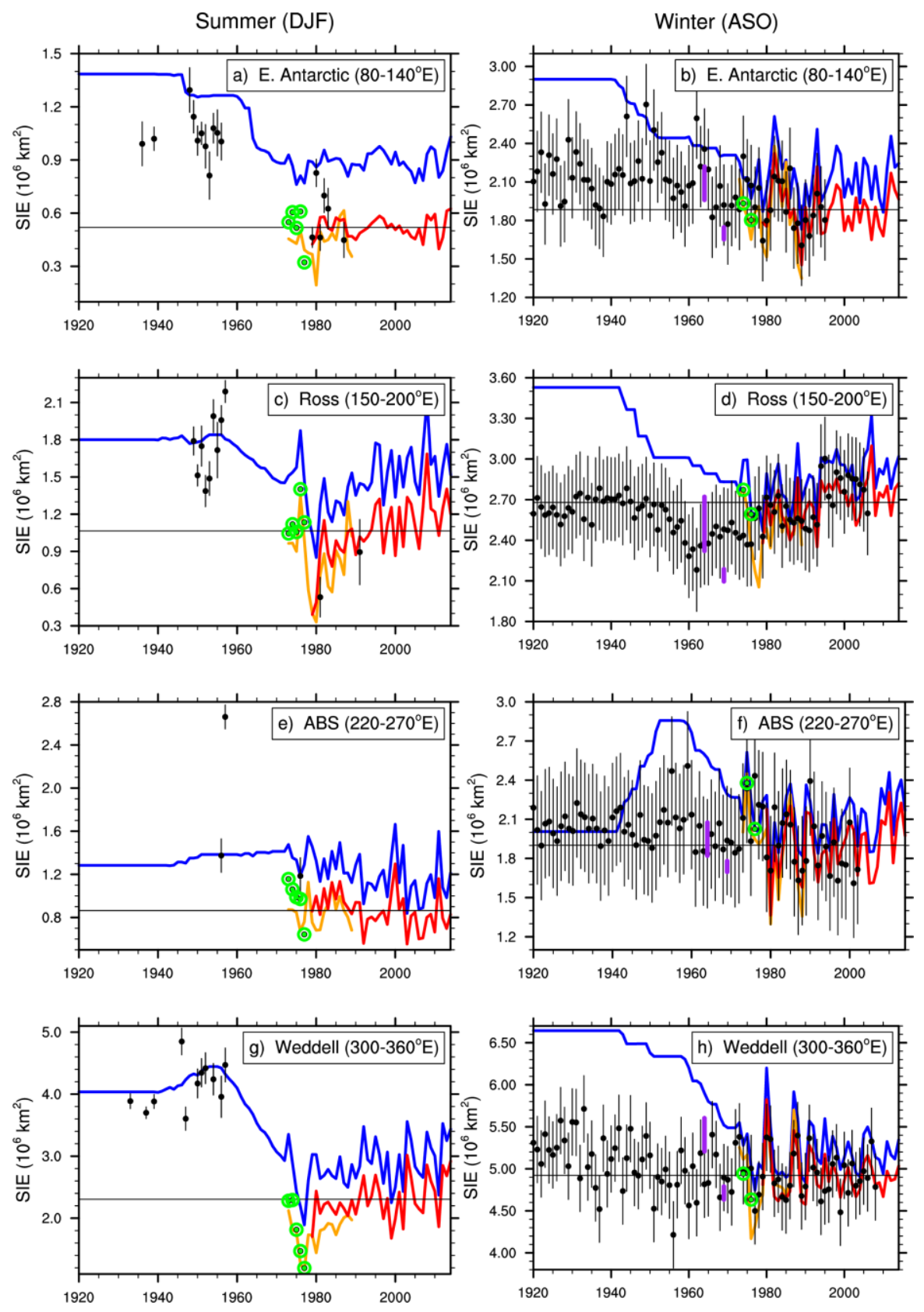

Figure 4 - Evolution of sector-integrated SIE since 1920, from monthly Goddard-merged SIC (red line); JIC sea ice area (orange line); HadISST2.2 monthly SIC (blue line; Titchner and Rayner, 2014); where available NIMBUS 1 and 3 (purple lines indicating uncertainty range); NIMBUS 5 ESMR (green markers) and proxy reconstructions (black dots, with uncertainty range. All summer reconstructions are based on whaling records (de la Mare, 2009). For winter reconstructions, East Antarctic is based on the Law Dome MSA record (Curran et al., 2003); Ross Sea is based on the Whitehall Glacier d-excess record (Sinclair et al., 2014); ABS reconstruction is based on the Antarctic Peninsula stacked MSA record (Abram et al., 2010); and the Weddell reconstruction is based on the SOFI duration (Murphy et al., 2014). Horizontal black lines show the 1979-2014 mean from the Goddard-merged data. 


\section{Physical mechanisms of change}

Sea ice responds to many different interactive processes in the atmosphere and ocean (Weeks, 2010). These include the advection of heat, the horizontal movement of sea ice by wind and ocean currents, and mixed layer freshwater fluxes such as precipitation, brine rejection and meltwater from icebergs, ice shelves and marine-terminating glaciers. In this section, we give an overview of these processes and their possible role in driving the observed trends described above.

\subsection{Atmospheric drivers}

Atmospheric processes, and in particular wind, are thought to explain most of the observed interannual variability and much of the trends in SO sea ice (Raphael, 2007; Lefebvre and Goosse, 2008; Massom et al., 2008; Holland and Kwok, 2012; Hosking et al., 2013; Raphael and Hobbs, 2014; Matear et al., 2015). Depending on their direction, meridional winds advect warm, moist air from lower latitudes or cold, dry air from the continent, affecting sea ice production and melt. Wind is also the major driver of sea ice motion (Assmann et al., 2005; Heil et al., 2006; Holland and Kwok, 2012). [Climatological patterns of sea ice drift around Antarctica also reflect climatological ocean surface current patterns, but these in turn are largely wind driven (e.g. Baines, 2006)].

Snowfall is a further factor affecting the growth and maintenance of sea ice, but in non-linear ways. On the one hand, a layer of snow impedes the thermodynamic growth of sea ice due to its low thermal conductivity, which is an order of magnitude less than that of ice (Sturm and Massom, 2009). Due to its high albedo and insulating effect, snow cover over the summer may also protect 
sea ice from surface melt certain regions (Eicken et al., 1995), but a significant portion of the melt is due to ocean heat flux underneath the ice rather than atmospheric warming and insolation at the surface (Gordon, 1981; Andreas and Ackley, 1982). However, when sufficient snow accumulates such that its mass depresses the ice surface below sea level, the resultant flooding creates a slush layer that can subsequently freeze into sea ice. In the SO, the rate of snowfall is more than sufficient for the flooding process to dominate the impedance of thermodynamic ice growth (Powell et al., 2005), and snow ice formation is an efficient means of thickening the ice or maintaining its thickness (Lytle and Ackley, 2001; Maksym and Markus, 2008). It is unclear whether precipitation changes have altered snow cover on the sea ice. Careful examination of atmospheric reanalysis data since 1989 indicates that there is no robust widespread precipitation trend over the sea ice zone, and there are large disagreements between the different reanalyses (Bromwich et al., 2011).

Changes in storm track activity and location may be a significant forcing factor, and there is an observed tendency towards fewer but more intense cyclones in the sea ice zone (Simmonds et al., 2003). Recent studies show that high-frequency stochastic atmospheric variability (i.e. weather) can interact with ocean mixed layer to produce long term variability in the SO sea ice (O'Kane et al., 2013), with the largest impacts in the East Antarctic and King Hakon VII sectors (Matear et al., 2015), sectors which have amongst the highest synoptic activity over the sea ice zone (Simmonds et al., 2003). Studies also show that wind-forced wave activity can penetrate a significant distance into the ice pack, facilitating break up of the pack (Liu and Mollo-Christensen, 1988; Kohout et al., 
2014), and there is a close spatial correlation between trends in significant wave height and SIE during both sea ice advance and retreat (Kohout et al., 2014).

The large-scale interaction between Antarctic sea ice and the atmosphere is complicated, since each sector responds to different atmospheric modes of variability, and no one single mode is a good predictor of sea ice response (Lefebvre and Goosse, 2008; Raphael and Hobbs, 2014). The dominant mode of atmospheric variability over the SO is the Southern Annular Mode (SAM), which can be broadly considered as an expression of the intensity of the zonal winds (Gong and Wang, 1999; Thompson and Wallace, 2000). A significant positive trend in the SAM has been observed since the mid -1960s (Gong and Wang, 1999; Kidson, 1999; Thompson et al., 2000; Marshall, 2003), implying an intensification of the westerly winds over much of the SO. From Ekman theory, westerly winds drive northward transport of the ice and thus an expansion of the SIE (Hall and Visbeck, 2002; Sen Gupta and England, 2006). However, recent modelling studies suggest that the positive SAM trend would drive a decrease in the SIE (Sigmond and Fyfe, 2010). Ferreira et al. (2015) potentially resolved this paradox by showing that sea ice initially expands in response to a positive SAM trend, but over longer timescales this drives Ekman pumping of warm circumpolar deepwater to the surface to reduce ice production; the timescale at which this response shifts is as yet unknown.

Although the zonal flow (of which the SAM is largely an expression) is the dominant feature of the SO atmosphere, the relative impact of meridional winds on sea ice coverage is far greater than their mean strength might suggest (Raphael, 2007; Yuan and Li, 2008; Hobbs and Raphael, 2010; Holland and Kwok, 2012; Hosking et al., 2013). This is because of the impact it has on local 
meridional transport of sea ice, and because meridional thermal advection is much greater than its zonal counterpart. Shifts in location of the meridional winds can have a greater effect on sea ice variability than changes in their strength (Raphael, 2007; Hobbs and Raphael, 2010; Holland and Kwok, 2012; Coggins and McDonald, 2015).

In the context of sea ice trends, one of the most important features of the circumpolar atmosphere's meridional flow is the Amundsen Sea Low, or ASL (Hosking et al., 2013; Turner et al., 2013c; Raphael et al., 2016). This is a quasistationary atmospheric low pressure anomaly at approximately $60^{\circ}-70^{\circ} \mathrm{S}$, with climatological mean zonal location that shifts from $220^{\circ} \mathrm{E}$ in winter to $250^{\circ} \mathrm{E}$ in summer (Hosking et al., 2013). It occurs as a result of zonal flow around the continental topography (Baines and Fraedrich, 1989) and therefore is closely related to the SAM (Lefebvre et al., 2004; Turner et al., 2013c). Cyclonic flow around this low pressure centre drives warm poleward winds into the Antarctic Peninsula/Bellingshausen Sea region, and a cold equatorward wind over the Ross Sea, with implications for the dipole in sea ice trends between these two regions (Lefebvre et al., 2004; Holland and Kwok, 2012; Hosking et al., 2013; Turner et al., 2015a; Turner et al., 2015b).

Holland and Kwok (2012) connected changes in autumn (April-June) SIC in the Ross and Amundsen seas to wind-driven sea ice motion trends, and Haumann et al. (2014) showed a similar relationship for annual mean trends. Figure 5a summarises this relationship for the 1992-2010 analysis period used by Holland and Kwok (2012). This shows a cyclonic trend centred over the Bellingshausen Sea that is consistent with a deepening ASL (Hosking et al., 2013), causing a warm, moist northerly airflow to the Bellingshausen Sea that 
reduces SIC and also delays the onset of sea ice growth (Stammerjohn et al., 2012). Sea ice growth in the Bellingshausen Sea is predominately thermodynamic rather than dynamic, making it susceptible to advection of warm air (Kimura and Wakatsuchi, 2011). In the Ross Sea, there is a positive SIC trend at the ice edge over the entire sector, that is consistent with ASL-related southerly wind trends. However, extending the analysis to the whole passive microwave period shows a different pattern (Figure 5b), There is still a ASLrelated northerly wind trend over the Bellingshausen Sea, albeit somewhat reduced, but in the Ross sea the SIC increase is largely confined to the western Ross Sea (i.e. west of the Ross Sea embayment). Due to an eastern shift in the ASL compared to Figure 5a, the meridional wind trends in this region are also weaker (Coggins and McDonald, 2015), and not so readily connected to the SIC trends. This suggests that sea ice changes in the Bellingshausen Sea are related to the deepening ASL, but in the western Ross Sea, while local wind trends may be responsible for the sea ice changes (Haumann et al., 2014), the role of the ASL in explaining these wind changes is not so clear. It should be noted that ice-ocean feedbacks may be able to sustain sea ice trends for some time after an initial atmospheric forcing (Goosse and Zunz, 2014), and that wind trends in the earlier period may have triggered an ongoing SIC increase. 


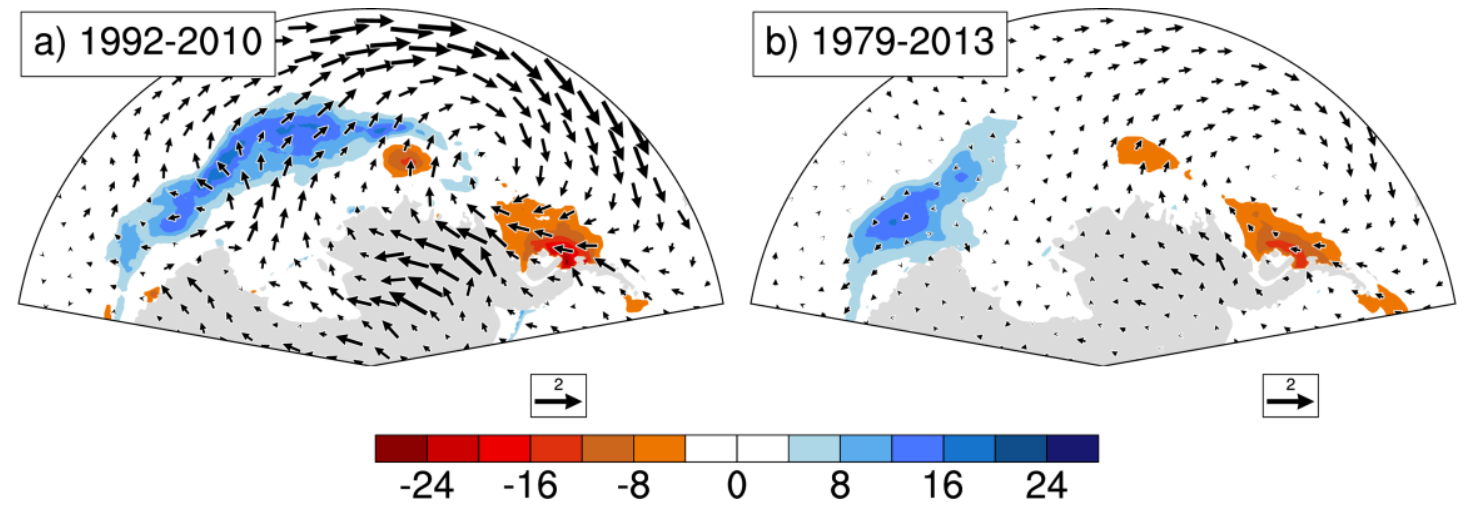

Figure 5 - April-June seasonal mean trends in SIC (\%/decade: shading) and ERAinterim 10m winds ( $\mathrm{ms}^{-1} /$ decade: vectors) for the analysis period of Holland and Kwok (2012), compared to the full passive microwave period.

Antarctic sea ice also has a strong response to tropical sea-surface temperature (SST) anomalies via the El-Niño Southern Oscillation (ENSO) (Gloersen, 1995; Simmonds and Jacka, 1995; Kwok and Comiso, 2002; Turner, 2004; Yuan, 2004; Simpkins et al., 2012). Atmospheric anomalies excited by tropical Pacific convection propagate south-eastwards by way of an atmospheric Rossby wave train to the high latitude south-eastern Pacific (Yu et al., 2011), a mode commonly referred to as the Pacific South-American mode (Karoly, 1989; Mo and Higgins, 1998; Mo, 2000; Mo and Paegle, 2001). The response is most evident in the eastern Ross and ABS sectors (Gloersen, 1995; Simmonds and Jacka, 1995; Kwok and Comiso, 2002; Turner, 2004; Yuan, 2004), and peaks during the late austral winter and spring (Mo and Higgins, 1998; Jin and Kirtman, 2009; Simpkins et al., 2012). During warm ENSO events (i.e. El Niños), a highpressure anomaly is set up centred at approximately $90^{\circ} \mathrm{W}, 55^{\circ} \mathrm{S}$, i.e. a weakened ASL (Turner, 2004; Yuan, 2004; Yuan and Li, 2008). The atmospheric response is quite non-linear; there is an asymmetry between the responses to warm and cold ENSO events (Houseago-Stokes and McGregor, 2000; Yuan, 2004; Simpkins et al., 2012), and the magnitude of the high latitude Southern Hemisphere 
teleconnection is highly variable. Whilst the fickleness of the teleconnection has been attributed to internal variability (Sterl et al., 2007), there is strong evidence that in fact the response to ENSO is modulated by the background state of the SAM. The ENSO teleconnection is only statistically significant when SAM is in a weak (i.e. neutral) phase, or when SAM is in phase with the driving ENSO event. That is to say that the teleconnection with El Niño is significant when the SAM is in a negative phase, and with La Niña when the SAM is in a positive phase (Fogt and Bromwich, 2006; Stammerjohn et al., 2008; Fogt et al., 2010).

Observation-based studies have shown that, although important for interannual variability, ENSO contributes little to the overall trends in Antarctic sea ice (Liu et al., 2004; Yu et al., 2011; Simpkins et al., 2012; Kohyama and Hartmann, 2016). However, it has been suggested that West Antarctic surface temperature changes may be related to multi-decadal modes of Pacific variability (Schneider and Steig, 2008; Ding et al., 2011; Okumura et al., 2012). There is also a possible link between multi-decadal tropical Atlantic variability and West Antarctic sea ice (Li et al., 2014; Simpkins et al., 2014), with a physical mechanism that is similar to the tropical Pacific teleconnection, i.e. a Rossby wave train excited by tropical SSTs which modulates the depth of the climatological ASL. Under warming tropical Atlantic conditions (as has been the case since 1979), the ASL tends to deepen, driving Bellingshausen and eastern Ross sea ice changes in winter (Li et al., 2014) and spring (Simpkins et al., 2014). This raises the question of whether the strong decadal variability in observed sea ice trends (Simpkins et al., 2013; Fan et al., 2014) can be attributed to tropical teleconnections. Hobbs et al. (2015) found that removing the linear signal of the Atlantic Multi-decadal Oscillation (AMO) and Inter-decadal Pacific Oscillation 
(IPO) indices from Antarctic SIE had some impact on the observed trends in those seasons, but not enough to explain the full Ross Sea trend. Additionally, there was no impact in the warmer seasons when the sea ice trends are strongest, as would be expected since atmospheric teleconnections to the high Southern latitudes are weak in the austral summer (Jin and Kirtman, 2009). In Figure 6, we summarise the potential impact of these major modes for the observed SIE trends. Consistent with Hobbs et al. (2015), tropical teleconnections (represented here by the IPO and AMO) explain little of the trend in any season. The positive SAM trend has its biggest impact in summer (Figure 6a), and may explain some of the decrease in the Bellingshausen Sea, but the signal is contrary to observed trends in the Amundsen and Weddell seas. The ASL intensity (ASLp) has a modest impact in all sectors/seasons except the Weddell Sea, where its effect is generally contrary to the observed trends. In fact, we find a weakening trend in the 1979-2013 ASL from the relative central pressure index of Hosking et al. (2013), in contrast to the strengthening over the same period reported by Turner et al. (2015b), using a different index that does not differentiate between changes in amplitude and location of the ASL. The Hosking et al. (2013) index attempts to separate the SAM from the ASL, whereas the Turner et al. (2015b) does not; since the SAM is already included in the analysis in Figure 6, we use the former index to avoid 'double-counting'. As an aside, we note that this suggests that much of the ASL strengthening is due to the positive SAM trend. The ASL longitude (ASLx) has the strongest impact (Coggins and McDonald, 2015), with a possible role in the increased winter and spring ice coverage in the eastern Ross Sea (Figures 6c and d). 
This simple analysis considers only the zero-lag relationship between the atmosphere and sea ice, but a confounding factor is the interaction between different seasons (in particular advance and retreat) discussed in section 2.2 which may induce time-lagged relationships, especially given the seasonal dependence of tropical teleconnections (Jin and Kirtman, 2009).
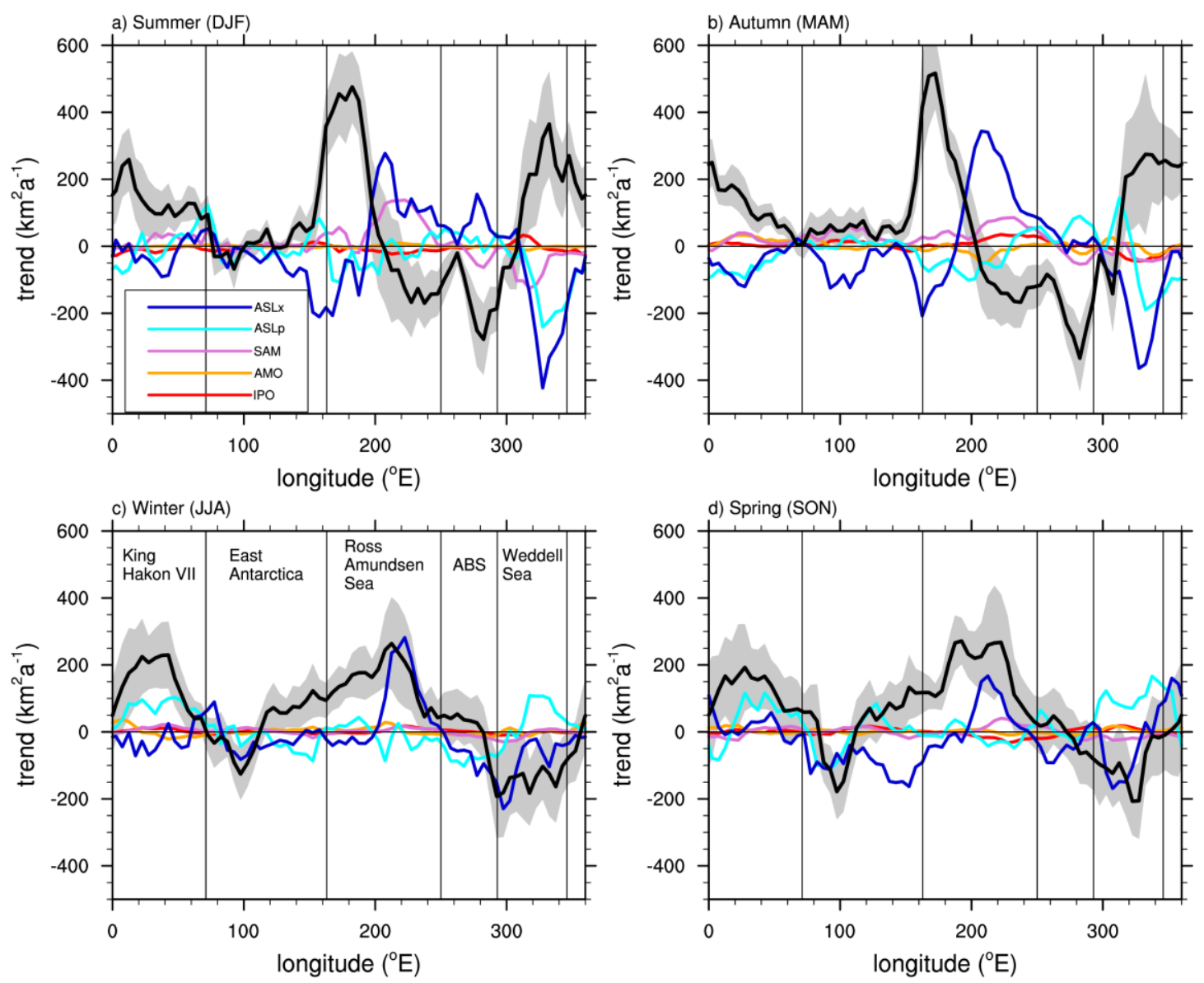

Figure 6-1979-2013 Trends in SIE by longitude (black line, with uncertainty shown by grey shading), with coloured lines showing the trends attributable to individual atmospheric modes. Each index was regressed against SIE by seasons, after removing the linear trend from the SIE and the indices. These transfer coefficients were used to estimate each index's SIE 'signal' (i.e. the variability of SIE attributable to that index alone), the trend of the signal was calculated and plotted. ASLx and ASLp refer to the ASL longitude and relative central pressure respectively. 
In summary, the critical role of the major modes of Southern Hemisphere atmospheric variability in defining the interannual variability of Antarctic sea ice is long established and undeniable. However, despite numerous studies considering the regional impact of atmospheric changes on Antarctic sea ice coverage, the observed trends defy a simple attribution to trends in these major modes. This is especially true of the Ross Sea sector, which alone contributes most of the observed increase in total sea ice coverage since 1979 (Parkinson and Cavalieri, 2012).

It is important to note that this does not mean that the atmosphere has no role to play. Ocean-atmosphere interactions may complicate the question beyond a simple ice motion/atmospheric thermal advection response. The ocean may explain sea ice responses to SAM changes that oppose each other, dependent on timescale (Ferreira et al., 2015). Sea ice-ocean feedbacks may be important in the transferral of sea ice anomalies from one season to the next (Stammerjohn et al., 2012; Holland et al., 2013; Holland, 2014), which may be particularly important for explaining the increased western Ross Sea ice coverage observed in all seasons. We discuss the important role of the ocean in modulating sea ice in the next section.

Finally, given the importance of the atmosphere, we consider the quality of large-scale atmospheric data over the SO. Most recent research into SO sea ice has relied to some extent on atmospheric reanalyses, which for the pre-satellite era rely on sparse data that are largely confined to coastal research stations. This means that the addition of satellite data (largely post-1979) has a large impact on the representation of the climate in some reanalyses, leading to spurious trends for periods that include both the pre- and post-satellite eras (Marshall, 
2003; Bromwich and Fogt, 2004). Some ocean-sea ice models, when forced with reanalysis-based surface boundary conditions, report a sea ice evolution over the late $20^{\text {th }}$ Century that is in broad agreement with observations (Goosse et al., 2009; Massonnet et al., 2013; Zunz and Goosse, 2015), whilst others fail to capture the observed trends (Zhang, 2007; Holland et al., 2014; Zhang, 2014; Downes et al., 2015). Much of this discrepancy seems to be due to the choice of forcing dataset, since even when the upper ocean temperature is constrained by simulations, differences in the surface wind forcing field can produce significant differences in modelled sea ice production and motion (Stossel et al., 2011).

Figure 7 compares post-1979 trends in sea level pressure (SLP) and nearsurface air temperature (SAT) for 4 widely-used atmospheric products: the NCEP-DOE Reanalysis 2 (NCEP2: Kanamitsu et al., 2002); the ECMWF ERAinterim reanalysis (ERA-INT: Dee et al., 2011); the Coordinated Ocean-Ice Reference Experiments v2 (CORE II: Large and Yeager, 2009); and the NCEP Climate Forecast System Reanalysis (CFSR: Saha et al., 2010). As can be seen, there is little consistency in the spatial pattern or magnitude of the trends from the products. Although validation is difficult in this data-poor region, ERA-INT is generally regarded as the best representation of the region's atmosphere (e.g. Bromwich et al., 2011), although the more recent and higher resolution CFSR data may be an improvement (Nicolas and Bromwich, 2014). However, we note that the ERA-INT SAT trend pattern has a very close agreement with the SIC trends in Figure 1 (as would be expected given the close relationship between sea ice and SAT), and sea ice assimilations using the ERA-INT surface temperature data reproduce SO sea ice trend patterns well (Goosse et al., 2009). The comparison in Figure 7, and the disagreements between model studies using 
different atmospheric products, highlights the importance of the atmosphere in explaining the sea ice trends, and the need for careful consideration in the choice of boundary forcing dataset in modelling studies. Note that atmospheric forcings do not uniquely ensure simulated sea ice fidelity; for example, Holland et al. (2014) used ERA-INT to force a sea ice assimilation that failed to capture the observed western Ross Sea trend, whereas Massonnet et al. (2013) used the apparently less reliable NCEP2 and obtained more realistic SIC trends. 

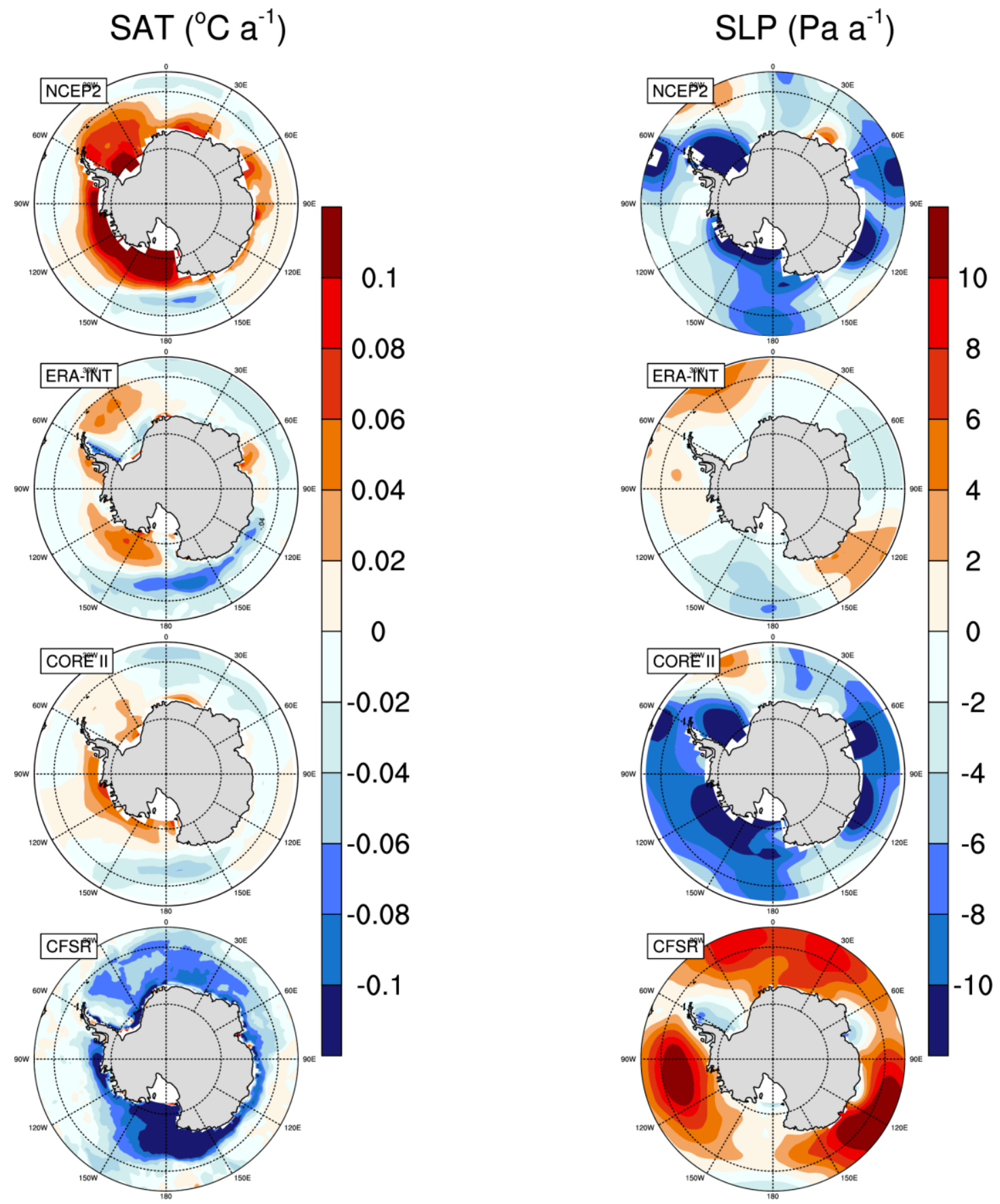

Figure 7 - 1979-2009 trends in near-surface air temperature (SAT, ${ }^{\circ} \mathrm{C}^{-1}$, left hand column) and sea level pressure (SLP, Pa $a^{-1}$, right hand column), for NCEP2, ERAINT, COREII and CFSR products

\subsection{Ocean drivers}

Although most of the Antarctic sea ice interannual variability can be attributed to the atmosphere, the ocean is a key component. The large annual cycle of Antarctic sea ice is only possible because interactions between wind, sea 
ice, solar radiation and the ocean mixed layer accelerate the spring melt (Gordon, 1981; Watkins and Simmonds, 1999). Sea ice forms when ocean water is cooled below its freezing point, and so the key primary ocean state variable is the temperature of the near-isothermal surface mixed layer. (Although the freezing point of surface seawater is a function of its salinity - saltier water has a lower freezing point - the dependence is just $-0.06{ }^{\circ} \mathrm{C}(\mathrm{PSU})^{-1}$ for a realistic range of surface salinities, and so this effect is minimal.) The mixed layer temperature is altered at the surface by incoming solar radiation (Watkins and Simmonds, 1999), and at the base of the mixed layer by entrainment of warm water; both processes are in turn affected by sea ice.

The vertical structure of the near-surface water column is highly seasonal in the sea ice zone due to ice-related heat and freshwater fluxes (e.g. Gordon, 1981; Martinson, 1990). A highly simplified conceptual model of the nearsurface ocean in the sea ice zone is of a cool, fresh mixed layer floating on relatively warm, salty Circumpolar Deep Water (CDW), where CDW is a water mass drawn from deep waters of the Atlantic, Pacific and Indian Ocean basins, and upwelled to the SO near-surface by Ekman pumping. During the autumn freeze period, brine rejection by sea ice formation densifies the surface water; the sinking of the rejected briny water drives vertical mixing which results in a permanent mixed layer of Winter Water with a depth of over $150 \mathrm{~m}$, and entrains the warmer, deep water into the mixed layer (Martinson, 1990; de Boyer Montégut, 2004). The vertical ocean heat flux due to this entrainment provides a thermal limit to Antarctic sea ice growth (Martinson and Wamser, 1990; Martinson and Iannuzzi, 1998). The deep mixed layer is maintained over the winter as the sea ice cover impedes ocean-atmosphere fluxes. In spring and 
summer, the sea ice melts, along with any accumulated snow cover. This sets up a relatively fresh surface seasonal mixed layer over the top of the Winter Water, with a depth of approximately 50m (de Boyer Montégut, 2004). The buoyancy of the fresh surface water is an impediment to entrainment of the warm salty deep water, and insolation warms the seasonal mixed layer over the summer, to further stabilise the near-surface waters. This seasonal cycle demonstrates how the temperature of the mixed layer is tied to the stratification of the water column. This means that feedbacks between ocean stratification and sea ice freeze/melt may be important in explaining the overall increase in SO sea ice and its regional and seasonal components.

Zhang (2007) demonstrated a mechanism by which sea ice coverage could increase under an increasing surface air temperature, similar to Martinson (1990). In his model, reduced sea ice production in the advance season decreases brine rejection and increases stratification. This reduces the entrainment of warm deep water into the winter mixed layer, and the spring melt is consequently reduced even more than the ice growth. Thus, there is a negative feedback though the ocean between autumn ice production and the subsequent summer sea ice. By contrast, other model studies suggest that an increase in ice coverage can lead to the same increased stratification (Goosse et al., 2009; Goosse and Zunz, 2014). By this mechanism, once the pack ice cover is established the surface water tends to be fresher when there is greater sea ice coverage. This again increases stratification and reduces melt by reducing the upwelling of warm water.

How can these two feedbacks, one positive and one negative, be resolved when they rely on essentially similar physical processes? Firstly, the effect of 
either feedback depends on the background state of the water column; in particular, the Zhang (2007) mechanism requires that the ocean heat flux from entrainment is greater than the surface warming that initially slowed the ice growth, a condition that is not necessary for the Goosse and Zunz (2014) process. This condition has been observed (Martinson, 1990), but there is a high spatial dependence. Figure 8 shows the location of Autumn (MAM) SIC trends in relation to the bathymetry. Trends in the Weddell and western Ross Sea sectors are predominately in the deep ocean domain, whereas the decrease in the Bellingshausen Sea is largely over the shelf; the processes in these regions may be quite different, even though the deeper water masses are surprisingly similar (Holland et al., 2010). Secondly, although neither mechanism requires a consideration of horizontal sea ice transport, the Goosse and Zunz (2014) mechanism could be invoked where sea ice anomalies have been driven by ice motion [e.g. the western Ross Sea (Holland and Kwok, 2012; Haumann et al., 2014)], whereas an implied requirement of Zhang (2007)'s negative feedback is that ice formation and melt anomalies are approximately co-located. Thirdly, there is a difference in timescales. In the Zhang (2007) process, the balance between net ice production and net melt occurs over the course of a single annual cycle and the atmospheric forcing is required in each growth season. In the Goosse and Zunz (2014) mechanism, there is a net downward pumping of salt, i.e. a net freshening of the surface, that can persist over years to decades. This is because during the winter growth period, the rejected brine is mixed into the deep Winter Water layer, but in the summer melt when freshwater is returned, the seasonal mixed layer is shallow and the surface layer freshening is more concentrated. 


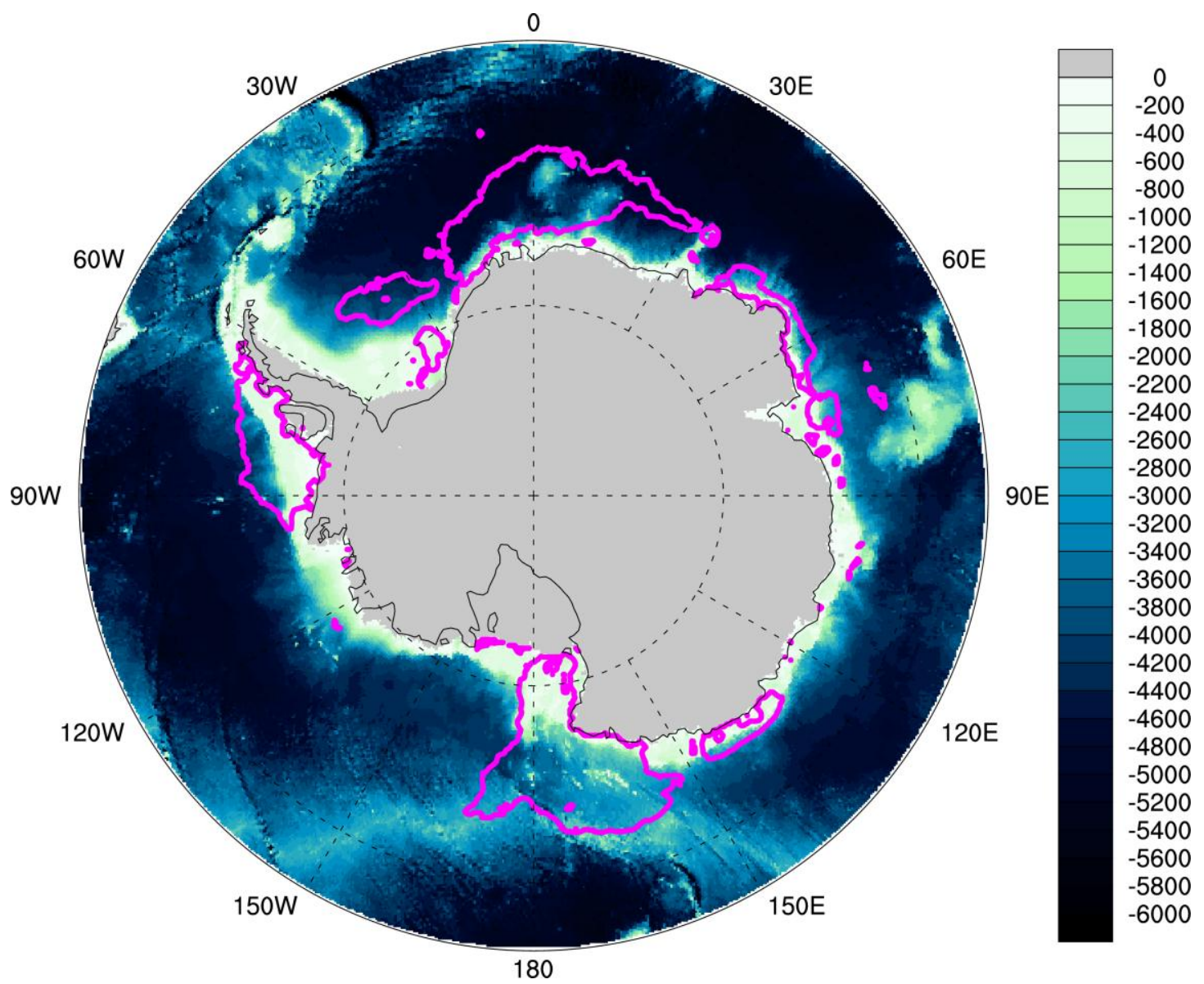

Figure 8 - Coarse resolution bathymetry of the SO, with magenta lines showing the boundaries of statistically significant MAM sea ice concentration trends (as per Figure 1b).

These processes were hypothesised from model experiments but both feedbacks have some agreement with observed trends. The western Ross Sea has a reduced rate of autumn sea ice expansion (Table 1), but this is counteracted by an even larger reduction in the spring melt leading to an overall summer increase in SIE, a pattern that is consistent with Zhang (2007), although there is no evidence of a surface warming in that region. However, in the Bellingshausen Sea, observed surface salinification has been linked to reduced sea ice production (Meredith and King, 2005), which is consistent with Goosse and Zunz (2014), although changes in sea ice transport could also play a role (Meredith et al., 2016). We also note that a data assimilation using the Goosse and Zunz 
(2014) model and forced by observed surface temperature was able to reproduce the spatial pattern and temporal evolution of late $20^{\text {th }}$ Century sea ice trends (Goosse et al., 2009), including the post-1960s decrease indicated by proxy records (Curran et al., 2003; Abram et al., 2010) and the subsequent increase over the passive microwave period. This indicates that the Goosse and Zunz (2014) mechanism is important in explaining the observed trends.

As the primary thermal sink of the climate system, the ocean is responsible for the sustenance or re-emergence of climate anomalies over periods longer than a few months. Stammerjohn et al. (2012) demonstrated an asymmetry in the time span of SO sea ice duration anomalies. The timing of spring ice retreat is significantly correlated with subsequent autumn ice advance, such that an earlier retreat results in a later ice advance, but there is no significant relationship between ice advance and subsequent ice retreat. Holland et al. (2013) confirmed this with a coupled model experiment, and furthermore found that SIC anomalies are not sustained over the summer period, but rather re-emerge during the autumn ice advance. Low sea ice coverage during retreat means that the ocean absorbs more solar radiation at a time when stratification is seasonally weak, and so the heat is transferred to depth. Over summer, the water column stratifies, and the surface no longer "feels" the heat content anomaly until autumn, when brine rejection breaks the stratification and the heat content anomaly returns to the ocean mixed layer. In models, this process seems to be confined to the Weddell Sea (Holland et al., 2013). Observations indicate a retreat-advance relationship throughout the western Antarctic sectors, but the mechanism proposed to explain this relationship in the ABS and western Ross sectors is somewhat different (Stammerjohn et al., 2012). There, 
an earlier retreat leads to increased absorption of solar radiation by the ocean causing near-surface heat anomalies, which remain in the summer mixed layer and delay the autumn onset of melt (and vice versa). The location of these different mechanisms again suggests a strong spatial dependence in the impact that ocean processes have on the sea ice.

As well as brine rejection and insolation, mechanical mixing has been observed as a mechanism for sea ice-ocean feedbacks (Venables and Meredith, 2014). Reduced winter ice cover allows greater for greater turbulent mixing driven by surface wind stress, and hence a reduced stratification at the end of winter; this allows greater uptake of heat into the summer mixed layer, and consequently reduced ice growth in the following autumn and winter. Hence, this process is a positive feedback that does not require sea ice-related freshwater fluxes.

The processes described above are feedbacks to changes in sea ice cover, and so they may modulate the amplitude of sea ice trends and variability but do not explain the root cause. It is possible that changes in the regional ocean circulation have a role in explaining the trend pattern. Observations (Schmidtko et al., 2014) and model experiments (Thoma et al., 2008) indicate that there has been an increased flow of warm CDW onto the Amundsen Sea continental shelf, driven by wind stress trends attributed to tropical Pacific variability (Steig et al., 2012), but there is considerable interannual variability (Dutrieux et al., 2014). Those studies were primarily concerned with ice shelf basal melt, rather than near-surface changes of relevance to sea ice. However, observations show that in the Bellingshausen Sea, both vertical and horizontal transport of CDW onto the continental shelf has increased the near surface ocean heat content (Martinson 
et al., 2008), with considerable implications for the decreasing ice coverage in the region. Away from the coast, increased westerly winds may be driving an increased upwelling of CDW, with obvious implications for ocean heat flux in the sea ice zone (Marshall et al., 2014; Ferreira et al., 2015).

\subsection{Ice shelf melt}

Considerable attention has been given to the hypothesis that freshwater input from melting ice shelves could change the water column sufficiently to cause an expansion of SO sea ice cover (Bintanja et al., 2013; Bintanja et al., 2015). Theoretically this could form a relatively fresh surface layer and increase near-surface stratification. Bintanja et al. (2013) used a coupled climate model to show that this effect could increase regional ice extent, although the spatially simplified freshwater forcing used in their experiment did not result in a replication of the observed distribution of trends. Subsequent experiments using more realistic freshwater fluxes confirmed an increased ice cover but, even with freshwater forcings much greater than Bintanja et al. (2013), the sea ice response was small (Swart and Fyfe, 2013; Pauling et al., 2016). The models used these studies were too coarse to capture the complex coastal ocean circulation that could theoretically transport melt water from the warming regions of the Bellingshausen and Amundsen seas to areas of sea ice increase.

The freshwater budget in the Ross Sea suggests that an import of freshwater is required to explain the observed freshening waters on the Ross Sea continental shelf (Jacobs and Giulivi, 2010; Comiso et al., 2011; Schmidtko et al., 2014). An increase in SO snowfall may have contributed to the increase in ice coverage by stabilising the water column (Marsland and Wolff, 2001; Liu and 
Curry, 2010), as well as increasing ice thickness by enhancing surface flooding and snow ice formation (Powell et al., 2005). However, in reanalyses there is limited evidence of a recent trend in precipitation over the sea ice (Bromwich et al., 2011), which indicates that the freshening must be sourced from ice sheet margin melt.

The current rate of total freshwater input from Antarctic grounded ice and ice shelves is estimated to be approximately $350 \pm 100 \mathrm{Gt} /$ year (Rye et al., 2014), equivalent to $0.01 \mathrm{~Sv}$ of freshwater flux. By comparison, the annual mean precipitation is $0.036 \mathrm{~Sv}$ over the seasonally ice-covered Ross Sea (defined here as $150-210^{\circ} \mathrm{E}$, and calculated from ERA-INT reanalysis). Unlike precipitation, however, basal meltwater is released at depth rather than at the surface where the melt water is buoyant compared to the surrounding seawater. It is not well established, however, whether this water reaches the near surface in sufficient quantities to affect sea ice production/melt, but surprisingly the depth of freshwater forcing in models has little impact on the sea ice response (Pauling et al., 2016).

There is also an observed freshening of Antarctic Bottom Water (AABW), equivalent to about half of the net freshwater input from ice shelf basal melt (Purkey and Johnson, 2013; van Wijk and Rintoul, 2014). Although the source of this freshening is unknown, model studies indicate that a decrease, not increase, in sea ice should result in a warming and volume reduction of AABW as observed (Bitz et al., 2006; Kirkman and Bitz, 2011), whereas input of meltwater is consistent with a warming and freshening AABW (Pauling et al., 2016). This suggests that the source of AABW freshening is most likely ice sheet melt water, and implies that only about half the melt water reaches the near surface where it 
can impact sea ice. There is, however, clear evidence in models (Pauling et al., 2016) and observations (Meredith et al., 2013; Randall-Goodwin et al., 2015) that some basal melt water reaches the near surface.

Kusahara and Hasumi (2014) forced a $20 \mathrm{~km}$ resolution (i.e. not eddy resolving) regional ocean model with realistic ice shelf freshwater fluxes, and simulated freshening signals at the surface in the western Ross Sea, sourced from the Ross and East Antarctic ice shelves. Freshening was greatest in the ABS, both at depth and at the surface. Importantly the model showed a thickening of late winter sea ice in all sectors, but no discernible impact on SIE in any region. They did not investigate seasons when the observed trends are most intense (i.e. autumn).

On balance, research to date suggests that freshwater input from ice sheet melt has had little influence on the observed sea ice changes, although it is possible that melt water has mitigated sea ice loss in the ABS. More work is required to determine whether this is true for all seasons. A further unknown is whether the effect of meltwater will increase in the future with the predicted acceleration of ice sheet mass loss (Golledge et al., 2015). Model experiments have shown that this may be the case (Bintanja et al., 2015), but with the same issues of coarse model resolution, unexplained discrepancies in model response, and unrealistic freshwater forcings that have confounded similar studies of the observed period.

\section{Role of anthropogenic forcing}

Inevitably, the question of whether the observed trends in SO sea ice are a response to anthropogenic climate forcing has received much interest (Bindoff et 
al., 2013), not least because the increased ice coverage in a warming world represents an apparent paradox, and is in striking contrast to the strong negative trends in the Arctic (Maksym et al., 2012). There is evidence of anthropogenic signals in some of the atmospheric modes that affect sea ice. Ice core studies indicate that the current positive trend in the SAM is unprecedented in the last millennium (Abram et al., 2014). For the summer and autumn seasons when sea ice trends are strongest, the SAM trend can be attributed to a combination of greenhouse gas forcing (GHG) and ozone depletion (Thompson and Solomon, 2002; Marshall et al., 2004; Arblaster and Meehl, 2006; Gillett et al., 2013; Christidis and Stott, 2015). However, as we have seen, the SAM alone is not sufficient to explain the observed sea ice trends (Lefebvre et al., 2004; Liu et al., 2004; Yu et al., 2011), and there is uncertainty as to the timescale at which a positive SAM trend should invoke an increase or decrease in Southern Ocean sea ice (Sigmond and Fyfe, 2010; Bitz and Polvani, 2012; Ferreira et al., 2015). The reduction in Bellingshausen Sea ice coverage is thought to be related to the deepening of the ASL, which as we have noted is closely related to the SAM. The observed ASL deepening is consistent with the expected response to anthropogenic forcing, in particular stratospheric ozone depletion (Fogt and Zbacnik, 2014; Fogt and Wovrosh, 2015), and ice core proxies for the last 2000 years suggest that the ASL deepening and associated sea ice reduction is extremely unusual, but not unprecedented (Steig et al., 2013). However, the observed deepening is within the range of internal variability of global coupled climate models (Turner et al., 2015b). Therefore there is some evidence, albeit equivocal, which would indicate that we might expect to see a sea ice response to anthropogenic forcing. 
When considering the role of climate forcings on SO sea ice, a number of points must be borne in mind. The first, which is a primary consideration in socalled 'detection and attribution' studies, is the problem of low signal-to-noise ratio, that is to say that climate change responses (the 'signal') are generally low compared to the internal variability of the system. Indeed, state-of-the-science techniques used in detection and attribution studies are designed to transform data to improve the signal-to-noise ratio (Hasselmann, 1993; Hegerl et al., 1996; Allen and Stott, 2003). The signal-to-noise ratio of the high latitude SO surface is particularly low. Multi-decadal variability is relatively strong at high latitudes (Monselesan et al., 2015) meaning that the 'noise' is large. At the same time, the anthropogenic signal at the SO surface is expected to be quite low. Whilst there is unequivocally a long-term warming over most of the planet's surface (Hartmann et al., 2013), this is not the case at the near-surface of the SO. This is because: a) sinking of dense waters near the Antarctic coast moves warming signals from the surface to the deep ocean, and further north the upwelling of CDW mutes the local surface response, leading to a delayed anthropogenic signal in the sea ice zone (Marshall et al., 2015); b) SO responses to ozone and greenhouse gas forcing may counteract one another, leading to a weak combined response, at least until the Southern Hemisphere ozone hole recovers (Marshall et al., 2014); and c) negative sea ice-ocean feedbacks (described in section 3.2) may limit the Antarctic sea ice response to anthropogenic forcings (Martinson, 1990; Zhang, 2007; Kirkman and Bitz, 2011). Hence, the anthropogenic response is expected to be much weaker at the SO surface compared to the Arctic. Therefore, it is entirely plausible that an anthropogenically-forced decrease in sea ice coverage is masked by large multi-decadal variability. 
As well as reliable observations of change, detection and attribution requires a theoretical expected response to given climate forcings, and an estimate of internal variability on longer time scales than are directly observed; generally both these requirements are fulfilled by model experiments. A number of investigations have used output from the Coupled Model Intercomparison Project v5 (CMIP5: Taylor et al., 2012) experiments for formal detection and attribution studies of total SO SIE, and we now consider the results of those experiments. Figure 9 compares observed SIE trends with the same trends from 90 realisations of the CMIP5 'historical' (i.e., all forcings) experiment. The observed trends are generally within the range of the model spread, except in two key regions, the western Ross and Bellingshausen seas and during summer and autumn. This indicates that the processes driving trends in these regions are not well represented in the models. The spread of simulated trends is quite wide at all longitudes, as a result of both differences between the models and internal variability. Spread is greater during the colder seasons. There is a particularly wide spread in the Weddell Sea, possibly due to a tendency towards Weddell deep convection events in the models (de Lavergne et al., 2014). 

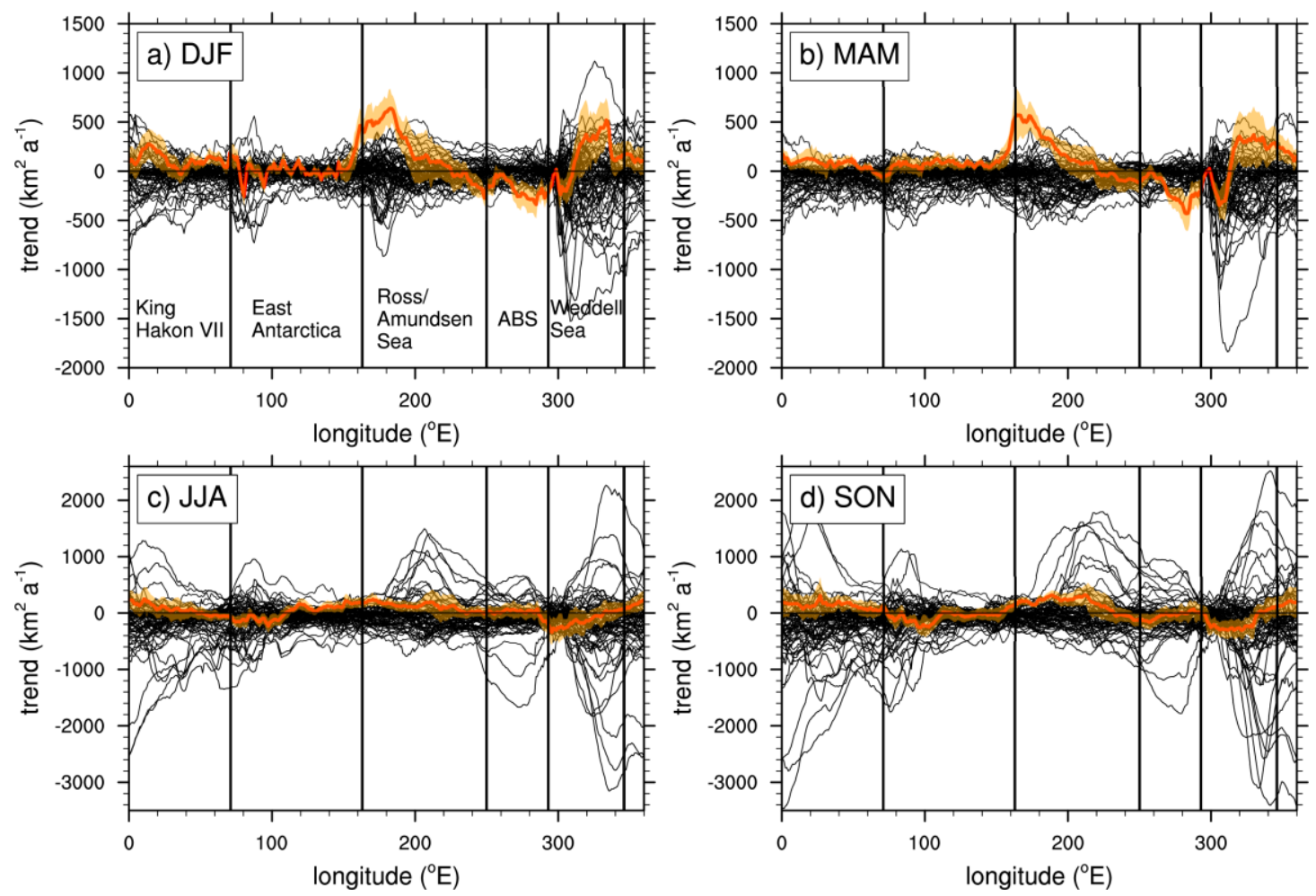

Figure 9 - 1979-2005 SIE trends by season, from passive microwave data (red line, with orange uncertainty), and from 90 members of the CMIP5 'historical' (i.e. allforcings) simulation (black lines). The list of models is summarised Appendix A. The model trends have been drift-corrected by removing the background linear trend from each model's control simulation.

To separate the forced signal from internal variability, a common approach is to take the mean across all ensemble members, as shown in Figure 10. The spatial and seasonal distribution of the estimated signal is markedly different from observed trends (Figure 2a), with the model ensemble-mean showing a more homogeneous pattern of decrease in almost all sectors and seasons. Also, the greatest model response occurs in the winter, and in the sectors affected by the Weddell Gyre (i.e. King Hakon VII and Weddell seas). Eisenman et al. (2011) argued that the lack of summer response in the models is due to the constraint that the Antarctic land mass places on summer sea ice variability; the northern extent of the Antarctic ice pack is unbounded by land (in contrast to the Arctic) and is free to expand/contract, whereas the Antarctic 
coast means that the summer extent can only retreat so far. Eisenman et al.

(2011) did not discuss why the same effect is not seen in observations, but we note that in fact the SO polar front provides an effective thermodynamic limit on winter ice extent (Martinson, 1990; Nghiem et al., 2016), which may not be adequately represented in the models. Interestingly the Ross Sea is the only region for which the model ensemble-mean trend is not statistically significant, highlighting the dynamic complexity of the region, and suggesting that the observed winter trends in the Ross Sea may be due to internal variability. The models capture an eastward propagation of autumn trends to the Weddell Sea, although the rate of propagation is faster than observed (Figure 2a), and it starts from the Ross rather than the Amundsen Sea.

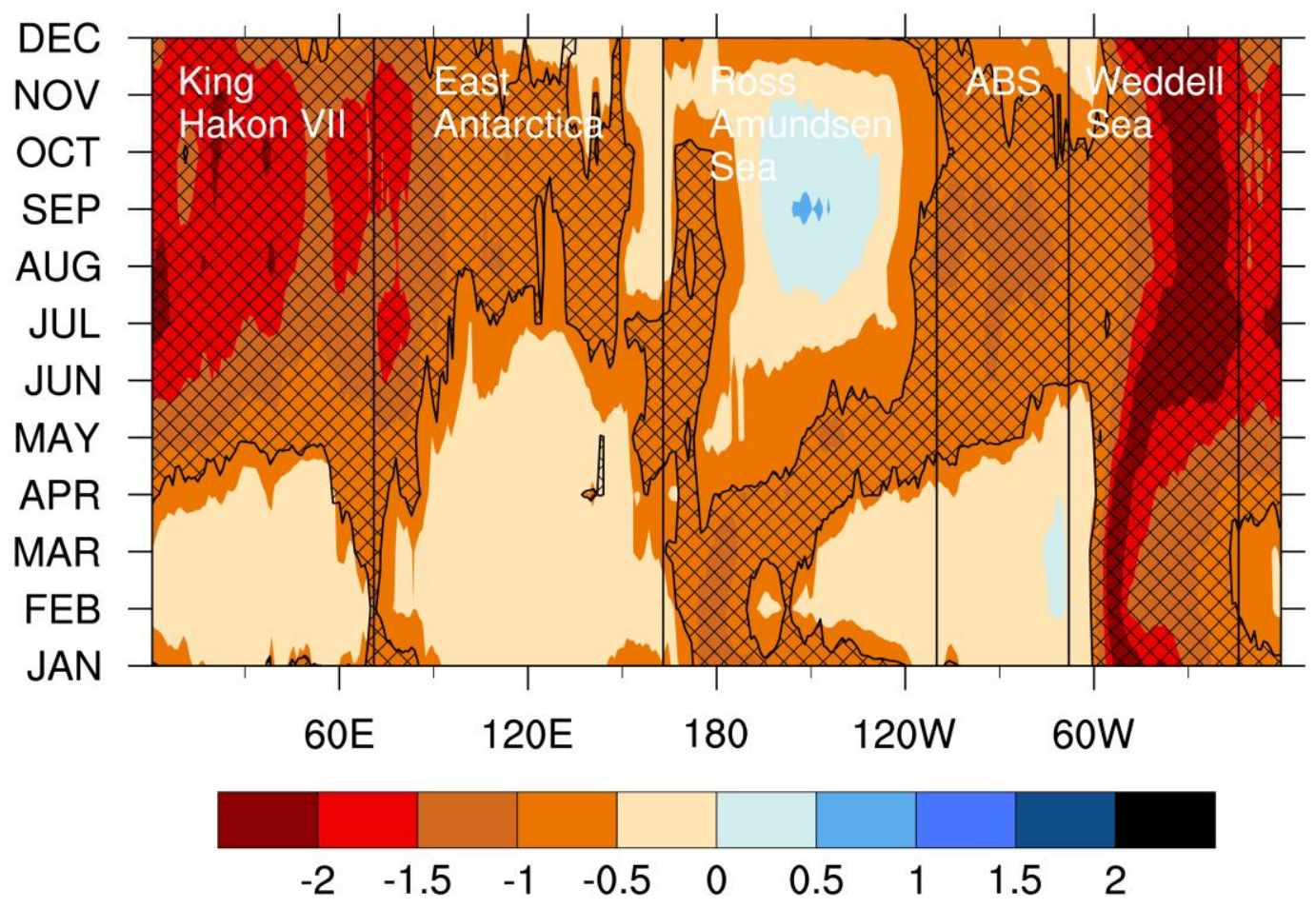


Figure 10 - 1979-2005 Ensemble-mean SIE trends $\left(10^{-2} \mathrm{~km}^{-2} \mathrm{a}^{-1}\right)$ from the CMIP5 'historical' (i.e. all-forcings) experiment. The ensemble comprises 90 members from 20 models (listed in Appendix A). Hatching shows regions where the mean trend is statistically significantly different from 0 , based on a 1-sample Student's T-test on the distribution of model ensemble-mean trends.

It is important to understand the role that individual climate forcings play in the trend pattern shown in Figure 10. Figure 11 shows the ensemble mean evolution of total SIE anomalies in 4 coupled models, under greenhouse gas forcing only, ozone forcing only, and all forcings experiments. (Natural forcings, i.e. solar and volcanic, and anthropogenic aerosols are not shown, but contribute little to the total SIE pattern.) The models simulate a small SIE decrease starting in the 1920s, which accelerates in the 1960s. The dominant forcing is from greenhouse gasses, with a relatively small response to ozone-depletion. Although not shown here, a similar result holds true for the individual sectors. 


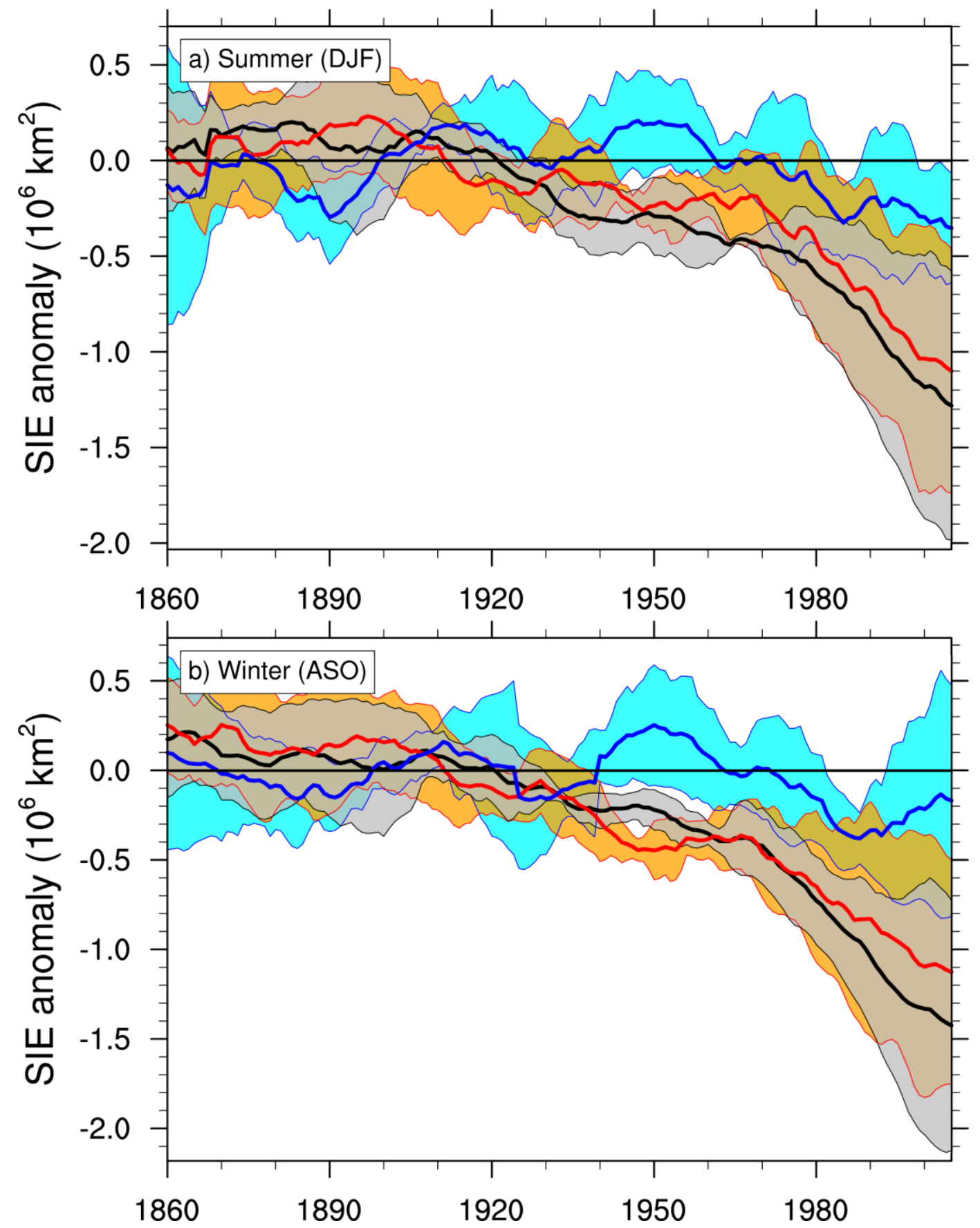

Figure 11 - Temporal evolution of a) Summer and b) Winter SIE from allforcings (black), greenhouse-gas forcing only (red) and ozone-forcing only (blue) CMIP5 experiments. Lines are plotted as anomalies with respect to the 1860-1950 mean, and have been smoothed by a 15-year moving average. Responses are ensemble means from the ACCESS1-3, CCSM4, CESM1-CAM5 and FGOALS-g2 experiments. Shading shows the uncertainty in the estimated response, i.e. the standard error across the model members at each time point; uncertainty is greater for experiments with fewer ensemble members (e.g. ozone-only). 
A number of studies have shown that both the observed increase in total SIE, and the simulated decrease due to anthropogenic forcing, are within the range of internal variability simulated by models under pre-industrial conditions (Mahlstein et al., 2013; Polvani and Smith, 2013; Swart and Fyfe, 2013; Zunz et al., 2013). It is important to stress that this does not necessarily mean that there is no response at all, even though the decrease in SIE in all sectors simulated by the models is modest. Those studies compared ensemble mean or individual simulated trends to the pre-Industrial control simulations; however, if the distribution of forced trends (rather than individual experiment results) is compared with the control simulations, there is a statistically significant difference, implying a non-zero forced response (Hobbs et al., 2015).

Motivated by the spatial heterogeneity of the observed sea ice trends, Hobbs et al. (2015) considered the pattern as well as the magnitude of SIE trends. They found that in summer and autumn, the spatial pattern of trends, and in particular the simultaneous opposing trends in the ABS and Ross Sea sectors, is outside the range of ABS-Ross co-variability in the CMIP5 control simulations. This raises the question of whether circumpolar total SIE is a suitable metric for detection and attribution studies, or whether the regional differences should be considered. We know that each sector responds to different atmospheric modes (Lefebvre and Goosse, 2008; Raphael and Hobbs, 2014), and a process-based understanding of the trends must therefore be based on regional studies. On the other hand, total SIE is a less noisy metric (due to spatial averaging) and, if the coupled models are correct and the expected anthropogenic response is homogeneous across all sectors, is a better metric for change detection. The answer rests on the whether the anthropogenic response is indeed as 
homogeneous as the models suggest, or whether the heterogeneous pattern of trends is a coherent zonally-asymmetric response to climate forcings.

Since recent studies have all relied to some degree on the results from the CMIP5 models, it is appropriate to consider the reliability of these models in reproducing the complex atmosphere and ocean circulations of the SO. The CMIP5 models are known to have strong biases in their mean sea ice coverage (Turner et al., 2013d; Meijers, 2014; Shu et al., 2015), and they overestimate interannual variance (Liu and Curry, 2010; Zunz et al., 2013). For summer (DJF), the 20 models used in Figures 9 and 10 have control run standard deviations of total Antarctic SIE that range from 50 to $250 \%$ of the $1979-2014$ observed standard deviation $\left(0.60 \times 10^{6} \mathrm{~km}^{2}\right)$; for late winter (ASO), the range is 120 to $900 \%$ of the observed standard deviation $\left(0.38 \times 10^{6} \mathrm{~km}^{2}\right)$. In the context of the responses shown in Figures 10 and 11, this means that the estimated anthropogenic response is either outside the range of internal variability or barely noticeable, depending on the choice of models in the ensemble. Since the true value of internal variability on multi-decadal and longer timescales is unknown (hence the need for model estimates), model selection for change detection is problematic and potentially subjective. For further discussion of the model selection problem, we refer the reader to Knutti (2010).

There are sound physical reasons to be sceptical of the magnitude of variability in the models. The CMIP5 models have significant biases in CDW temperature which is correlated with model SIE biases (Meijers, 2014), and the SO mixed layer tends to be too shallow in the models (Sallee et al., 2013; Meijers, 2014), which could make sea ice freeze/melt more sensitive to atmospheric forcing. Sea ice-ocean feedbacks can lead to considerable multi-decadal sea ice 
variability (Goosse and Zunz, 2014), which is impossible to test in the absence of reliable long-term observational data. Also, there may be multi-decadal modes of SO variability affecting the sea ice zone that require representation of eddy-mean flow interaction (Le Bars et al., 2016), but almost none of the CMIP5 models are eddy-resolving.

Even models with interannual variances that agree with observations may do so for the wrong reason e.g., excessive ice motion counteracting thermodynamic deficiencies (Uotila et al., 2014), and that could affect the model response to external forcings. In order to reproduce the sea ice trend patterns effectively, it is essential to correctly reproduce changes in the atmospheric circulation, but this is challenging for coarse-resolution global coupled models in the complex topography of coastal Antarctica. Haumann et al. (2014) suggested that the resolution of global coupled climate models is insufficient to resolve changes in topographically forced features of the atmospheric circulation, such as the ASL and meridional winds in the Ross Sea embayment. This has clear implications for detection and attribution studies using such global coupled models, and may explain the discrepancy between models and observations in the western Ross Sea. It has been shown that finer resolution regional models can significantly improve the representation of the Antarctic atmosphere (Bromwich et al., 2013) and the ocean circulation (Kirtman et al., 2012), and some of the uncertainty might be resolved by studies using multi-decadal highresolution simulations.

CMIP5 models do not include dynamic ice sheet and ice shelf components, and it has been suggested that the apparent discrepancy occurs because there is no corresponding freshwater input from ice sheet and shelf melt (Bintanja et al., 
2013). Sensitivity studies show, however, that the inclusion of freshwater forcings leads to only a modest improvement in model-observation agreement (Swart and Fyfe, 2013; Zunz and Goosse, 2015).

The short duration of the passive microwave record is another barrier to certainty in the detection and attribution problem, which several studies have attempted to address. Gagné et al. (2015) combined early NIMBUS data with modern satellite observations, and compared the 50-year record with CMIP5 simulations. They showed that a decrease in September total SIE from the 1960s to the late-1990s, and the subsequent increase, is not inconsistent with the CMIP5 models; results were less certain for early winter (May-July), with no evidence of a decline since the NIMBUS period. Proxy reconstructions of $20^{\text {th }}$ Century SIE offer a further opportunity for longer-term detection and attribution. The records in Figure 4 show some agreements with the models, with a decrease in SIE starting in the 1960s, but the Ross Sea is a notable exception (at least in winter, Figure 4d). However, there are continuing methodological challenges in using proxies for formal detection/attribution. First is the issue that empirical, linear reconstruction methods tend to underestimate low-frequency signals (von Storch et al., 2004), including trends and long-term variability. Secondly, there are currently a limited number of reliable proxy records with proven relationships to SO SIE (Abram et al., 2013); hence independent verification of reconstructions is not possible. Last but not least is the high observational uncertainty inherent in reconstructed time series. An implicit assumption with attribution methods that aim to maximise the signal-to-noise ratio is that observational error is small compared to the internal 
variability of the climate system (Hasselmann, 1993; Hegerl et al., 1996; Allen and Stott, 2003). As can be seen in Figure 4, this is not true in the case of proxy reconstructions. An appropriate treatment of this uncertainty source must be developed in any detection/attribution studies using proxies, which is not a trivial problem.

In summary, detection and attribution work to date indicates that the observed trends in Antarctic SIE are largely within the range of simulated internal variability, and an anthropogenic response cannot be unequivocally detected. The increase in western Ross Sea ice coverage, which is the major contributor to the positive trend in total coverage since 1979, is outside this range in summer and autumn. More work is required to verify whether the multi-decadal evolution is well represented by existing proxies that extend back beyond the satellite passive microwave era. To inform future detection and attribution efforts, it is essential to understand whether or not the spatial pattern of Antarctic sea ice trends could be anthropogenic. Finally, detection and attribution to date has been exclusively concerned with SIE, whereas other metrics, in particular sea ice seasonality (timings of annual advance and retreat and resultant duration), are important to consider in the context of anthropogenic impacts on the Antarctic climate system.

\section{Summary}

Since 1979, there have been significant observed trends in SO sea ice coverage (extent and concentration) and duration, with an overall increase in total SIE. Trends in SIE are robust to changes in the satellite observing system and retrieval method, although trends in SIC are more uncertain, especially in 
the marginal ice zone. The trends have a strong spatial and seasonal dependence. They are marked by decreased coverage in the ABS, and increased coverage in the western Ross Sea. This general pattern holds true for all seasons but is more intense summer and autumn, and in the winter trends are only statistically significant in the western Ross Sea. The Weddell Sea has a statistically significant increase in summer sea ice coverage (which also affects the adjacent King Hakon VII Sea), but a statistically insignificant reduction in winter.

Trends in sea ice duration largely follow the same spatial pattern (i.e. longer duration in the western Ross Sea, and shorter duration in the Bellingshausen Sea), due to changes in the timing of both advance and retreat. The seasonal dependence of ice coverage trends seems to be related to changes in the growth and melt seasons, such that changes in the timing and intensity of the spring melt result in strong summer trends, which are partially offset by changes in the autumn freeze. Feedbacks with the upper ocean are thought to play an important role in this seasonal trend pattern, such that an earlier (later) spring ice melt results in increased (decreased) ice production in autumn.

Proxy records indicate that there has been a decrease in summer sea ice extent in all sectors, and a decrease in winter sea ice extent in the Amundsen, Bellingshausen and East Antarctic sectors starting in the 1960s. Proxies also indicate that the Ross Sea increase dates back to the 1960s. There has been little change over the $20^{\text {th }}$ Century in Weddell Sea winter ice cover. There remain considerable uncertainties over the reliability of these reconstructions, and further independent proxies are required to validate these results.

The lack of reliable long-term estimates of sea ice thickness is a significant barrier to understanding these trends and their impacts. Change detection, 
process analysis, and investigation of the impact of SO sea ice changes on the global climate all require budget calculations of sea ice production and melt. Surface freshwater fluxes are intimately related to the problem of estimating snow mass on the ice, which is a confounding factor for sea ice thickness retrievals, as well as an important component of the surface freshwater budget.

Significant atmospheric trends have been observed over the same period as the sea ice trends, and in particular an anthropogenically-forced shift towards a positive phase of the SAM, and an attendant increase in circumpolar westerlies over the SO. It is not clear whether this would be expected to force an increase or decrease in SIE over the 3-4 decades of observed trends, and observational studies suggest that the SAM trend explains only a part of the sea ice trend pattern. Teleconnections with multi-decadal tropical Pacific and Atlantic variability in SST have been suggested as a contributing factor, but the magnitude of their influence on trends is not yet well-established; an initial analysis presented here indicates that it may be modest. The deepening of the Amundsen Sea Low (ASL) has been a focus of recent research, and certainly this deepening is consistent with some of the observed sea ice trends, in particular the loss of ice and warming of the Bellingshausen Sea, and an increase in some seasons in the eastern Ross Sea. However, its relationship to increased ice coverage in the western Ross Sea is not so clear. Although the ASL deepening is consistent with a response to anthropogenic forcing, the observed trend is not distinguishable from simulated internal variability in coupled models. It is unclear whether global coupled models adequately represent zonally asymmetric atmospheric changes over the Antarctic sea ice region, and this is a considerable source of uncertainty in detection and attribution. 
There is as yet no robust evidence that changes in the ocean, including anomalous freshening from West Antarctic Ice Sheet melt, has been a primary driver of the sea ice trends. However, it is likely that mixed-layer feedback processes between sea ice and ocean have had a role in modulating the sea ice trends. There appears to be a spatial dependence on where these processes are important, and rigorously identifying where these feedbacks occur would be a significant advance in our understanding. Compared to studies relating sea ice variability and change to atmospheric drivers, research into the effect of the ocean relies much more on model studies. This reflects the sparseness of hydrographic observations, and the difficulties of taking hydrographic profiles during advance and retreat seasons. The Argo network has revolutionised our understanding of the global ocean over the last decade (Riser et al., 2016), but standard Argo floats are not designed to survive under the ice, or in the shallow shelf regions that make up much of the sea ice production locations.

Improvements in float technology that allow Argo floats to survive in seasonally ice-covered seas are under way, and provide hope in the future for much greater hydrographic profiling (Wong and Riser, 2011). In the meantime, a novel source of reliable hydrographic data in the sea ice zone has been from instrumented elephant seals. These profiles of temperature and salinity reach to depths of $2000 \mathrm{~m}$ and date back to 2004 (Roquet et al., 2014), and have proved valuable in studies of sea ice-ocean interactions (Ohshima et al., 2013).

There is currently no evidence that the observed sea ice trends are anthropogenic. Coupled climate experiments, on which detection and attribution rely, indicate that the expected response to climate forcings since 1979 is a decrease in almost all sectors, with the strongest signal in winter, and the 
dominant forcing being increased greenhouse gas concentrations. This signal is small compared to internal variability, but there is a large spread amongst the models in the magnitude of SO sea ice variability, which greatly reduces certainty in detection and attribution statements. An unresolved question is whether the spatially heterogeneous pattern of trends is due to internal variability (as suggested by studies of the ASL) or part of a coherent forced response. For this reason it is not clear whether total circumpolar SIE is an appropriate metric for attribution studies - given its relatively low signal-to-noise ratio - or whether the spatial pattern of trends must be considered. A possible solution to this uncertainty could be the use of higher resolution regional models, which have been shown to have an improved representation of the complex atmosphere and ocean circulation over the sea ice zone. As yet, detection and attribution has been concerned solely with sea ice extent, but other metrics merit investigation.

Duration in particular has importance for ecosystems, as well as commercial implications due to its importance for ship logistics and access to research bases, as well as fisheries. There is clearly much work to be done in terms of improved observing systems, model developments and detailed analysis before the sea ice research community is able to make a confident statement regarding the current and future trajectory of Southern Ocean sea ice.

\section{Acknowledgements}

The authors are indebted to William de la Mare for providing his whale catch data, Kate Sinclair for the Whitehall Glacier excess-deuterium record, and Holly Titchner for providing the HadISST2.2 sea ice concentration data. The authors express their gratitude to Paul Holland and an anonymous reviewer for their invaluable comments and help in improving this manuscript. Data analysis and visualisation was performed using NCL (http://dx.doi.org/10.5065/D6WD3XH5). We acknowledge the World Climate Research Programme's Working Group on Coupled Modeling, which is 
responsible for CMIP, and we thank the climate modeling groups (listed in Appendix A) for producing and making available their model output. For CMIP the U.S. Department of Energy's Program for Climate Model Diagnosis and Intercomparison provides coordinating support and led development of software infrastructure in partnership with the Global Organization for Earth System Science Portals. This work was supported by the Australian Government's Cooperative Research Centres Programme through the Antarctic Climate and Ecosystems Cooperative Research Center (ACE CRC), and contributes to AAS Project 4116. SS acknowledges support and contributions from the National Science Foundation Office of Polar Programs Palmer LongTerm Ecological Project (ANT-1440435).

\section{Appendix A}

\begin{tabular}{|lcccc|}
\hline Model name & Citation & $\begin{array}{c}\text { historical } \\
\text { members }\end{array}$ & $\begin{array}{c}\text { HistoricalGHG } \\
\text { members }\end{array}$ & $\begin{array}{c}\text { HistoricalO3 } \\
\text { members }\end{array}$ \\
\hline ACCESS1-0 & Bi et al. (2013) & 2 & & \\
ACCESS1-3 & Bi et al. (2013) & 3 & & \\
BCC-CSM1-1-M & Xiao-Ge et al. (2013) & 3 & 3 & 3 \\
BCC-CSM1-1 & Xiao-Ge et al. (2013) & 3 & 1 & 3 \\
CCSM4 & Gent et al. (2011) & 8 & & \\
CESM1-CAM5 & Hurrell et al. (2013) & 3 & & \\
CNRM-CM5 & Mignot and Bony (2013) & 10 & & \\
CSIRO-Mk3-6 & Jeffrey et al. (2013) & 10 & & \\
CanESM2 & Yang and Saenko (2012) & 4 & & \\
FGOALS-g2 & Li et al. (2013) & 3 & & \\
GFDL-CM3 & Griffies et al. (2011) & 5 & & \\
HadGEM2-ES & Martin et al. (2011) & 5 & & \\
IPSL-CM5A-LR & Mignot and Bony (2013) & 6 & & \\
IPSL-CM5A-MR & Mignot and Bony (2013) & 3 & & \\
MIROC-ESM & Watanabe et al. (2011) & 3 & & \\
MIROC5 & Watanabe et al. (2010) & 5 & & \\
MPI-ESM-LR & Jungclaus et al. (2013) & 3 & & \\
MPI-ESM-MR & Jungclaus et al. (2013) & 3 & & \\
MRI-CGCM3 & Yukimoto et al. (2012) & 5 & & \\
NorESM1-M & Bentsen et al. (2012) & 3 & \\
\hline Total & & 90 & & \\
\hline Table A1 $-S u m b$ & & & \\
\hline
\end{tabular}

Table A1 - Summary of CMIP5 models (with appropriate citations) used in Figures 8 and 9, including the number of ensemble members used from the historical (i.e. all-forcings), historicalGHG (i.e. greenhouse gas forcing only) and historical03 (i.e. ozone-depletion only) experiments.

\section{References}

Abram, N. J., E. W. Wolff, and M. A. J. Curran, 2013: A review of sea ice proxy information from polar ice cores. Quaternary Sci Rev, 79, 168-183, 10.1016/j.quascirev.2013.01.011. 
Abram, N. J., R. Mulvaney, F. Vimeux, S. J. Phipps, J. Turner, and M. H. England, 2014: Evolution of the Southern Annular Mode during the past millennium. Nature Climate Change, 4, 564-569, 10.1038/NCLIMATE2235.

Abram, N. J., E. R. Thomas, J. R. McConnell, R. Mulvaney, T. J. Bracegirdle, L. C. Sime, and A. J. Aristarain, 2010: Ice core evidence for a 20th century decline of sea ice in the Bellingshausen Sea, Antarctica. J Geophys Res-Atmos, 115, Artn D23101 10.1029/2010jd014644.

Ackley, S., P. Wadhams, J. C. Comiso, and A. P. Worby, 2003: Decadal decrease of Antarctic sea ice extent inferred from whaling records revisited on the basis of historical and modern sea ice records. Polar Res, 22, 19-25, Doi 10.1111/J.17518369.2003.Tb00091.X.

Agosta, C., X. Fettweis, and R. Datta, 2015: Evaluation of the CMIP5 models in the aim of regional modelling of the Antarctic surface mass balance. The Cryosphere, 9, 2311-2321, 10.5194/tc-9-2311-2015.

Alexandrov, V., S. Sandven, J. Wahlin, and O. M. Johannessen, 2010: The relation between sea ice thickness and freeboard in the Arctic. Cryosphere, 4, 373-380, 10.5194/tc-4-373-2010.

Allen, M. R., and P. A. Stott, 2003: Estimating signal amplitudes in optimal fingerprinting, part I: theory. Clim Dynam, 21, 477-491, 10.1007/s00382-0030313-9.

Andreas, E. L., and S. F. Ackley, 1982: On the Differences in Ablation Seasons of Arctic and Antarctic Sea Ice. J Atmos Sci, 39, 440-447, Doi 10.1175/15200469(1982)039<0440:Otdias>2.0.Co;2.

Arblaster, J. M., and G. A. Meehl, 2006: Contributions of external forcings to southern annular mode trends. Journal of Climate, 19, 2896-2905, Doi 10.1175/Jcli3774.1.

Assmann, K. M., H. H. Hellmer, and S. S. Jacobs, 2005: Amundsen Sea ice production and transport. Journal of Geophysical Research-Oceans, 110, Artn C12013

10.1029/2004jc002797.

Baines, P. G., 2006: Coastal and Regional Currents of Antarctica. Encyclopaedia of the Antarctic, R. Riffenburgh, Ed., Routledge.

Baines, P. G., and K. Fraedrich, 1989: Topographic Effects on the Mean Tropospheric Flow Patterns around Antarctica. J Atmos Sci, 46, 3401-3415, Doi 10.1175/1520-0469(1989)046<3401:Teotmt>2.0.Co;2.

Bentsen, M., and Coauthors, 2012: The Norwegian Earth System Model, NorESM1-M - Part 1: Description and basic evaluation. Geoscientific Model Development Discussions, 5, 2843-2931, 10.5194/gmdd-5-2843-2012. 
Bi, D., and Coauthors, 2013: The ACCESS coupled model: description, control climate and evaluation. Australian Meteorological and Oceanographic Journal, 63, 41-64.

Bindoff, N. L., and Coauthors, 2013: Detection and Attribution of Climate Change: from Global to Regional. Climate Change 2013: The Physical Science Basis. Contribution of Working Group I to the Fifth Assessment Report of the Intergovernmental Panel on Climate Change, T. D. Stocker, and alia, Eds., Cambridge University Press, 967-952.

Bintanja, R., G. J. Van Oldenborgh, and C. A. Katsman, 2015: The effect of increased fresh water from Antarctic ice shelves on future trends in Antarctic sea ice. Annals of Glaciology, 56, 120-126, 10.3189/2015AoG69A001.

Bintanja, R., G. J. van Oldenborgh, S. S. Drijfhout, B. Wouters, and C. A. Katsman, 2013: Important role for ocean warming and increased ice-shelf melt in Antarctic sea-ice expansion. Nat Geosci, 6, 376-379, 10.1038/NGE01767.

Bitz, C. M., and L. M. Polvani, 2012: Antarctic climate response to stratospheric ozone depletion in a fine resolution ocean climate model. Geophysical Research Letters, 39, Artn L20705 $10.1029 / 2012 \mathrm{gl053393.}$

Bitz, C. M., P. R. Gent, R. A. Woodgate, M. M. Holland, and R. Lindsay, 2006: The influence of sea ice on ocean heat uptake in response to increasing CO2. Journal of Climate, 19, 2437-2450, Doi 10.1175/Jcli3756.1.

Bracegirdle, T. J., D. B. Stephenson, J. Turner, and T. Phillips, 2015: The importance of sea ice area biases in 21st century multimodel projections of Antarctic temperature and precipitation. Geophysical Research Letters, 42, 10,832-810,839, 10.1002/2015gl067055.

Bromwich, D. H., and R. L. Fogt, 2004: Strong trends in the skill of the ERA-40 and NCEP-NCAR reanalyses in the high and midlatitudes of the southern hemisphere, 1958-2001. Journal of Climate, 17, 4603-4619, Doi 10.1175/3241.1.

Bromwich, D. H., J. P. Nicolas, and A. J. Monaghan, 2011: An Assessment of Precipitation Changes over Antarctica and the Southern Ocean since 1989 in Contemporary Global Reanalyses. Journal of Climate, 24, 4189-4209, 10.1175/2011JCLI4074.1.

Bromwich, D. H., F. O. Otieno, K. M. Hines, K. W. Manning, and E. Shilo, 2013: Comprehensive evaluation of polar weather research and forecasting model performance in the Antarctic. J Geophys Res-Atmos, 118, 274-292, 10.1029/2012JD018139.

Cavalieri, D. J., 1994: A Microwave Technique for Mapping Thin Sea-Ice. Journal of Geophysical Research-Oceans, 99, 12561-12572, Doi 10.1029/94jc00707.

Cavalieri, D. J., and C. L. Parkinson, 2012: Arctic sea ice variability and trends, 1979-2010. Cryosphere, 6, 881-889, 10.5194/tc-6-881-2012. 
Cavalieri, D. J., C. L. Parkinson, and K. Y. Vinnikov, 2003: 30-Year satellite record reveals contrasting Arctic and Antarctic decadal sea ice variability. Geophysical Research Letters, 30, Artn 1970

10.1029/2003gl018031.

Cavalieri, D. J., C. L. Parkinson, P. Gloersen, J. C. Comiso, and H. J. Zwally, 1999:

Deriving long-term time series of sea ice cover from satellite passive-microwave multisensor data sets. Journal of Geophysical Research-Oceans, 104, 1580315814, Doi 10.1029/1999jc900081.

Christidis, N., and P. A. Stott, 2015: Changes in the geopotential height at $500 \mathrm{hPa}$ under the influence of external climatic forcings. Geophysical Research Letters, 42, 10,798-710,806, 10.1002/2015gl066669.

Coggins, J. H. J., and A. J. McDonald, 2015: The influence of the Amundsen Sea Low on the winds in the Ross Sea and surroundings: Insights from a synoptic climatology. J Geophys Res-Atmos, 120, 2167-2189, 10.1002/2014JD022830.

Comiso, J. C., 1986: Characteristics of Arctic Winter Sea Ice from Satellite Multispectral Microwave Observations. Journal of Geophysical Research-Oceans, 91, 975-994, Doi 10.1029/Jc091ic01p00975.

Comiso, J. C., and F. Nishio, 2008: Trends in the sea ice cover using enhanced and compatible AMSR-E, SSM/I, and SMMR data. Journal of Geophysical ResearchOceans, 113, Artn C02s07

10.1029/2007jc004257.

Comiso, J. C., R. Kwok, S. Martin, and A. L. Gordon, 2011: Variability and trends in sea ice extent and ice production in the Ross Sea. Journal of Geophysical ResearchOceans, 116, 10.1029/2010jc006391.

Constable, A. J., and Coauthors, 2014: Climate change and Southern Ocean ecosystems I: how changes in physical habitats directly affect marine biota. Glob Chang Biol, 20, 3004-3025, 10.1111/gcb.12623.

Cotte, C., and C. Guinet, 2007: Historical whaling records reveal major regional retreat of Antarctic sea ice. Deep-Sea Res Pt I, 54, 243-252, 10.1016/j.dsr.2006.11.001.

Curran, M. A., T. D. van Ommen, V. I. Morgan, K. L. Phillips, and A. S. Palmer, 2003: Ice core evidence for Antarctic sea ice decline since the 1950s. Science, 302, 1203-1206, 10.1126/science.1087888.

de Boyer Montégut, C., 2004: Mixed layer depth over the global ocean: An examination of profile data and a profile-based climatology. Journal of Geophysical Research, 109, 10.1029/2004jc002378.

de la Mare, W. K., 1997: Abrupt mid-twentieth-century decline in Antarctic seaice extent from whaling records. Nature, 389, 57-60, 10.1038/37956. 
de la Mare, W. K., 2009: Changes in Antarctic sea-ice extent from direct historical observations and whaling records. Climatic Change, 92, 461-493, 10.1007/s10584-008-9473-2.

de Lavergne, C., J. B. Palter, E. D. Galbraith, R. Bernardello, and I. Marinov, 2014: Cessation of deep convection in the open Southern Ocean under anthropogenic climate change. Nature Climate Change, 4, 278-282, doi:10.1038/nclimate2132.

Dedrick, K. R., K. Partington, M. Van Woert, C. A. Bertoia, and D. Benner, 2001: U.S. National/Naval Ice Center Digital Sea Ice Data and Climatology. Can J Remote Sens, 27, 457-475, 10.1080/07038992.2001.10854887.

Dee, D. P., and Coauthors, 2011: The ERA-Interim reanalysis: configuration and performance of the data assimilation system. QJ Roy Meteor Soc, 137, 553-597, 10.1002/qj.828.

Delille, B., and Coauthors, 2014: Southern Ocean CO2 sink: The contribution of the sea ice. Journal of Geophysical Research-Oceans, 119, 6340-6355, 10.1002/2014JC009941.

Deutsches Hydrographisches Institute, 1950: Atlas of ice conditions in the North Atlantic Ocean and general charts of the ice conditions of the North and South Polar regions. D. H. Institute, Ed.

Ding, Q. H., E. J. Steig, D. S. Battisti, and M. Kuttel, 2011: Winter warming in West Antarctica caused by central tropical Pacific warming. Nat Geosci, 4, 398-403, 10.1038/NGE01129.

Downes, S. M., and Coauthors, 2015: An assessment of Southern Ocean water masses and sea ice during 1988-2007 in a suite of interannual CORE-II simulations. Ocean Modelling, 94, 67-94, 10.1016/j.ocemod.2015.07.022.

Ducklow, H., and Coauthors, 2012: The marine ecosystem of the West Antarctic Peninsula. Antarctica: An Extreme Environment in a Changing World, A. Rogers, N. Johnston, A. Clarke, and E. Murphy, Eds., Blackwell.

Ducklow, H. W., and Coauthors, 2013: West Antarctic Peninsula: An IceDependent Coastal Marine Ecosystem in Transition. Oceanography, 26, 190-203.

Dupont, T. K., and R. B. Alley, 2005: Assessment of the importance of ice-shelf buttressing to ice-sheet flow. Geophysical Research Letters, 32, Artn L04503 $10.1029 / 2004$ gl022024.

Dutrieux, P., and Coauthors, 2014: Strong Sensitivity of Pine Island Ice-Shelf Melting to Climatic Variability. Science, 343, 174-178, 10.1126/science.1244341.

Edinburgh, T., and J. J. Day, 2016: Estimating thge extent $\mathrm{f}$ Antarctic summer sea ice druing the Heroic Age of Exploration. The Cryosphere Discussions, in review, 10.5194/tc-2016-90. 
Eicken, H., H. Fischer, and P. Lemke, 1995: Effects of the snow cover on Antarctic sea ice and potential modulation of its response to climate change. Annals of Glaciology, Vol 21, 1995, 369-376.

Eisenman, I., W. N. Meier, and J. R. Norris, 2014: A spurious jump in the satellite record: has Antarctic sea ice expansion been overestimated? The Cryosphere, $\mathbf{8}$, 1289-1296, 10.5194/tc-8-1289-2014.

Eisenman, I., T. Schneider, D. S. Battisti, and C. M. Bitz, 2011: Consistent Changes in the Sea Ice Seasonal Cycle in Response to Global Warming. Journal of Climate, 24, 5325-5335, 10.1175/2011JCLI4051.1.

Fan, T. T., C. Deser, and D. P. Schneider, 2014: Recent Antarctic sea ice trends in the context of Southern Ocean surface climate variations since 1950. Geophysical Research Letters, 41, 2419-2426, 10.1002/2014GL059239.

Ferreira, D., J. Marshall, C. M. Bitz, S. Solomon, and A. Plumb, 2015: Antarctic Ocean and Sea Ice Response to Ozone Depletion: A Two-Time-Scale Problem. Journal of Climate, 28, 1206-1226, 10.1175/JCLI-D-14-00313.1.

Fogt, R. L., and D. H. Bromwich, 2006: Decadal variability of the ENSO teleconnection to the high-latitude South Pacific governed by coupling with the southern annular mode. Journal of Climate, 19, 979-997, Doi 10.1175/Jcli3671.1.

Fogt, R. L., and E. A. Zbacnik, 2014: Sensitivity of the Amundsen Sea Low to Stratospheric Ozone Depletion. Journal of Climate, 27, 9383-9400, 10.1175/JCLID-13-00657.1.

Fogt, R. L., and A. J. Wovrosh, 2015: The Relative Influence of Tropical Sea Surface Temperatures and Radiative Forcing on the Amundsen Sea Low. Journal of Climate, 28, 8540-8555, 10.1175/JCLI-D-15-0091.1.

Fogt, R. L., D. H. Bromwich, and K. M. Hines, 2010: Understanding the SAM influence on the South Pacific ENSO teleconnection. Clim Dynam, 36, 1555-1576, 10.1007/s00382-010-0905-0.

Frolicher, T. L., J. L. Sarmiento, D. J. Paynter, J. P. Dunne, J. P. Krasting, and M. Winton, 2015: Dominance of the Southern Ocean in Anthropogenic Carbon and Heat Uptake in CMIP5 Models. Journal of Climate, 28, 862-886, 10.1175/JCLI-D14-00117.1.

Gagné, M. È., N. P. Gillett, and J. C. Fyfe, 2015: Observed and simulated changes in Antarctic sea ice extent over the past 50 years. Geophysical Research Letters, 42, 90-95, 10.1002/2014gl062231.

Gallaher, D. W., G. G. Campbell, and W. N. Meier, 2014: Anomalous Variability in Antarctic Sea Ice Extents During the 1960s With the Use of Nimbus Data. IEEE Journal of Selected Topics in Applied Earth Observations and Remote Sensing, 7, 881-887, 10.1109/JSTARS.2013.2264391. 
Gent, P. R., and Coauthors, 2011: The Community Climate System Model Version 4. J Climate, 24, 4973-4991, Doi 10.1175/2011jcli4083.1.

Giles, K. A., S. W. Laxon, and A. P. Worby, 2008: Antarctic sea ice elevation from satellite radar altimetry. Geophysical Research Letters, 35, Artn L03503 $10.1029 / 2007 \mathrm{gl031572.}$

Gillett, N. P., J. C. Fyfe, and D. E. Parker, 2013: Attribution of observed sea level pressure trends to greenhouse gas, aerosol, and ozone changes. Geophysical Research Letters, 40, 2302-2306, 10.1002/grl.50500.

Gloersen, P., 1995: Modulation of Hemispheric Sea-Ice Cover by Enso Events. Nature, 373, 503-506, Doi 10.1038/373503a0.

Godin, R. H., and D. G. Barnett, 1979: Inventory of Snow Cover and Sea Ice DataGD-7, 25-37 pp.

Golledge, N. R., D. E. Kowalewski, T. R. Naish, R. H. Levy, C. J. Fogwill, and E. G. W. Gasson, 2015: The multi-millennial Antarctic commitment to future sea-level rise. Nature, 526, 421-+, 10.1038/nature15706.

Gong, D. Y., and S. W. Wang, 1999: Definition of Antarctic Oscillation Index. Geophysical Research Letters, 26, 459-462, Doi 10.1029/1999gl900003.

Goosse, H., and V. Zunz, 2014: Decadal trends in the Antarctic sea ice extent ultimately controlled by ice-ocean feedback. Cryosphere, 8, 453-470, 10.5194/tc8-453-2014.

Goosse, H., W. Lefebvre, A. de Montety, E. Crespin, and A. H. Orsi, 2009: Consistent past half-century trends in the atmosphere, the sea ice and the ocean at high southern latitudes. Clim Dynam, 33, 999-1016, 10.1007/s00382-0080500-9.

Gordon, A. L., 1981: Seasonality of Southern-Ocean Sea Ice. J Geophys Res-Oc Atm, 86, 4193-4197, Doi 10.1029/Jc086ic05p04193.

Griffies, S. M., and Coauthors, 2011: The GFDL CM3 Coupled Climate Model: Characteristics of the Ocean and Sea Ice Simulations. J Climate, 24, 3520-3544, Doi 10.1175/2011jcli3964.1.

Haas, C., M. Nicolaus, S. Willmes, A. Worby, and D. Flinspach, 2008: Sea ice and snow thickness and physical properties of an ice floe in the western Weddell Sea and their changes during spring warming. Deep-Sea Res Pt Ii, 55, 963-974, 10.1016/j.dsr2.2007.12.020.

Hall, A., and M. Visbeck, 2002: Synchronous variability in the southern hemisphere atmosphere, sea ice, and ocean resulting from the annular mode. Journal of Climate, 15, 3043-3057, Doi 10.1175/15200442(2002)015<3043:Svitsh>2.0.Co;2.

Hartmann, D. L., and Coauthors, 2013: Observations: Atmosphere and Surface. 
Hasselmann, K., 1993: Optimal Fingerprints for the Detection of Time-Dependent Climate-Change. Journal of Climate, 6, 1957-1971, Doi 10.1175/15200442(1993)006<1957:Offtdo>2.0.Co;2.

Haumann, F. A., D. Notz, and H. Schmidt, 2014: Anthropogenic influence on recent circulation-driven Antarctic sea ice changes. Geophysical Research Letters, 41, 8429-8437, 10.1002/2014GL061659.

Hegerl, G. C., H. vonStorch, K. Hasselmann, B. D. Santer, U. Cubasch, and P. D. Jones, 1996: Detecting greenhouse-gas-induced climate change with an optimal fingerprint method. Journal of Climate, 9, 2281-2306, Doi 10.1175/15200442(1996)009<2281:Dggicc >2.0.Co;2.

Heil, P., C. W. Fowler, and S. E. Lake, 2006: Antarctic sea-ice velocity as derived from SSM/I imagery. Ann Glaciol-Ser, 44, 361-366, Doi $10.3189 / 172756406781811682$.

Hobbs, W. R., and M. N. Raphael, 2010: The Pacific zonal asymmetry and its influence on Southern Hemisphere sea ice variability. Antarct Sci, 22, 559-571, $10.1017 /$ S0954102010000283.

Hobbs, W. R., N. L. Bindoff, and M. N. Raphael, 2015: New Perspectives on Observed and Simulated Antarctic Sea Ice Extent Trends Using Optimal Fingerprinting Techniques. Journal of Climate, 28, 1543-1560, 10.1175/JCLI-D14-00367.1.

Holland, M. M., E. Blanchard-Wrigglesworth, J. Kay, and S. Vavrus, 2013: Initialvalue predictability of Antarctic sea ice in the Community Climate System Model 3. Geophysical Research Letters, 40, 2121-2124, 10.1002/grl.50410.

Holland, P. R., 2014: The seasonality of Antarctic sea ice trends. Geophysical Research Letters, 41, 4230-4237, 10.1002/2014GL060172.

Holland, P. R., and R. Kwok, 2012: Wind-driven trends in Antarctic sea-ice drift. Nat Geosci, 5, 872-875, 10.1038/NGE01627.

Holland, P. R., A. Jenkins, and D. M. Holland, 2010: Ice and ocean processes in the Bellingshausen Sea, Antarctica. Journal of Geophysical Research: Oceans, 115, n/a-n/a, 10.1029/2008JC005219.

Holland, P. R., N. Bruneau, C. Enright, M. Losch, N. T. Kurtz, and R. Kwok, 2014: Modeled Trends in Antarctic Sea Ice Thickness. Journal of Climate, 27, 37843801, 10.1175/JCLI-D-13-00301.1.

Hosking, J. S., A. Orr, G. J. Marshall, J. Turner, and T. Phillips, 2013: The Influence of the Amundsen-Bellingshausen Seas Low on the Climate of West Antarctica and Its Representation in Coupled Climate Model Simulations. Journal of Climate, 26, 6633-6648, 10.1175/JCLI-D-12-00813.1.

Houseago-Stokes, R. E., and G. R. McGregor, 2000: Spatial and temporal patterns linking southern low and high latitudes during south Pacific warm and cold 
events. Int J Climatol, 20, 793-801, Doi 10.1002/1097-

0088(20000615)20:7<793::Aid-Joc502>3.0.Co;2-9.

Hurrell, J. W., and Coauthors, 2013: The Community Earth System Model A Framework for Collaborative Research. B Am Meteorol Soc, 94, 1339-1360, 10.1175/BAMS-D-12-00121.1.

Iudicone, D., G. Madec, B. Blanke, and S. Speich, 2008: The role of Southern Ocean surface forcings and mixing in the global conveyor.J Phys Oceanogr, 38, 13771400, 10.1175/2008JP03519.1.

Ivanova, N., O. M. Johannessen, L. T. Pedersen, and R. T. Tonboe, 2014: Retrieval of Arctic Sea Ice Parameters by Satellite Passive Microwave Sensors: A Comparison of Eleven Sea Ice Concentration Algorithms. Ieee T Geosci Remote, 52, 7233-7246, 10.1109/TGRS.2014.2310136.

Ivanova, N., and Coauthors, 2015: Inter-comparison and evaluation of sea ice algorithms: towards further identification of challenges and optimal approach using passive microwave observations. Cryosphere, 9, 1797-1817, 10.5194/tc-91797-2015.

Jacobs, S. S., and C. F. Giulivi, 2010: Large Multidecadal Salinity Trends near the Pacific-Antarctic Continental Margin. Journal of Climate, 23, 4508-4524, 10.1175/2010jcli3284.1.

Jeffrey, S., and Coauthors, 2013: Australia's CMIP5 submission using the CSIROMk3.6 model. Australian Meteorological and Oceanographic Journal, 63, 1-13.

Jin, D., and B. P. Kirtman, 2009: Why the Southern Hemisphere ENSO responses lead ENSO. J Geophys Res-Atmos, 114, Artn D23101 10.1029/2009jd012657.

Johnson, G. C., 2008: Quantifying Antarctic Bottom Water and North Atlantic Deep Water volumes. Journal of Geophysical Research-Oceans, 113, Artn C05027 10.1029/2007jc004477.

Jungclaus, J. H., and Coauthors, 2013: Characteristics of the ocean simulations in the Max Planck Institute Ocean Model (MPIOM) the ocean component of the MPIEarth system model. J Adv Model Earth Sy, 5, 422-446, Doi 10.1002/Jame.20023.

Kanamitsu, M., W. Ebisuzaki, J. Woollen, S. K. Yang, J. J. Hnilo, M. Fiorino, and G. L. Potter, 2002: Ncep-Doe Amip-Ii Reanalysis (R-2). B Am Meteorol Soc, 83, 16311643, 10.1175/BAMS-83-11-1631.

Karoly, D. J., 1989: Southern-Hemisphere Circulation Features Associated with Elnino - Southern Oscillation Events. Journal of Climate, 2, 1239-1252, Doi 10.1175/1520-0442(1989)002<1239:Shcfaw>2.0.Co;2.

Kennicutt, M. C., and Coauthors, 2015: A roadmap for Antarctic and Southern Ocean science for the next two decades and beyond. Antarct Sci, 27, 3-18, $10.1017 /$ S0954102014000674. 
Kidson, J. W., 1999: Principal modes of Southern Hemisphere low-frequency variability obtained from NCEP-NCAR reanalyses. Journal of Climate, 12, 28082830, Doi 10.1175/1520-0442(1999)012<2808:Pmoshl>2.0.Co;2.

Kidston, J., A. S. Taschetto, D. W. J. Thompson, and M. H. England, 2011: The influence of Southern Hemisphere sea-ice extent on the latitude of the midlatitude jet stream. Geophysical Research Letters, 38, Artn L15804 10.1029/2011gl048056.

Kimura, N., and M. Wakatsuchi, 2011: Large-scale processes governing the seasonal variability of the Antarctic sea ice. Tellus $A, 63,828-840$, 10.1111/j.1600-0870.2011.00526.x.

King, J. C., and S. A. Harangozo, 1998: Climate change in the western Antarctic Peninsula since 1945: observations and possible causes. Annals of Glaciology, Vol 27, 1998, 27, 571-575.

Kirkman, C. H., and C. M. Bitz, 2011: The Effect of the Sea Ice Freshwater Flux on Southern Ocean Temperatures in CCSM3: Deep-Ocean Warming and Delayed Surface Warming. Journal of Climate, 24, 2224-2237, 10.1175/2010JCLI3625.1.

Kirtman, B. P., and Coauthors, 2012: Impact of ocean model resolution on CCSM climate simulations. Clim Dynam, 39, 1303-1328, 10.1007/s00382-012-1500-3.

Knutti, R., 2010: The end of model democracy? Climatic Change, 102, 395-404, 10.1007/s10584-010-9800-2.

Kohout, A. L., M. J. Williams, S. M. Dean, and M. H. Meylan, 2014: Storm-induced sea-ice breakup and the implications for ice extent. Nature, 509, 604-607, $10.1038 /$ nature13262.

Kohyama, T., and D. L. Hartmann, 2016: Antarctic Sea Ice Response to Weather and Climate Modes of Variability*. Journal of Climate, 29, 721-741, 10.1175/jclid-15-0301.1.

Krinner, G., O. Magand, I. Simmonds, C. Genthon, and J. L. Dufresne, 2007: Simulated Antarctic precipitation and surface mass balance at the end of the twentieth and twenty-first centuries. Clim Dynam, 28, 215-230, 10.1007/s00382-006-0177-x.

Kurtz, N. T., and T. Markus, 2012: Satellite observations of Antarctic sea ice thickness and volume. Journal of Geophysical Research-Oceans, 117, Artn C08025 10.1029/2012jc008141.

Kusahara, K., and H. Hasumi, 2014: Pathways of basal meltwater from Antarctic ice shelves: A model study. Journal of Geophysical Research-Oceans, 119, 56905704, 10.1002/2014JC009915.

Kwok, R., 2010: Satellite remote sensing of sea-ice thickness and kinematics: a review. J Glaciol, 56, 1129-1140. 
Kwok, R., and J. C. Comiso, 2002: Southern Ocean climate and sea ice anomalies associated with the Southern Oscillation. Journal of Climate, 15, 487-501, Doi 10.1175/1520-0442(2002)015<0487:Socasi>2.0.Co;2.

Kwok, R., and T. Maksym, 2014: Snow depth of the Weddell and Bellingshausen sea ice covers from IceBridge surveys in 2010 and 2011: An examination. Journal of Geophysical Research-Oceans, 119, 4141-4167, 10.1002/2014JC009943.

Large, W. G., and S. G. Yeager, 2009: The global climatology of an interannually varying air-sea flux data set. Clim Dynam, 33, 341-364, 10.1007/s00382-0080441-3.

Le Bars, D., J. P. Viebahn, and H. A. Dijkstra, 2016: A Southern Ocean mode of multidecadal variability. Geophysical Research Letters, 43,

10.1002/2016GL068177.

Lefebvre, W., and H. Goosse, 2008: An analysis of the atmospheric processes driving the large-scale winter sea ice variability in the Southern Ocean. Journal of Geophysical Research-Oceans, 113, Artn C02004

10.1029/2006jc004032.

Lefebvre, W., H. Goosse, R. Timmermann, and T. Fichefet, 2004: Influence of the Southern Annular Mode on the sea ice-ocean system. Journal of Geophysical Research-Oceans, 109, Artn C09005 10.1029/2004jc002403.

Leonard, K. C., and T. Maksym, 2011: The importance of wind-blown snow redistribution to snow accumulation on Bellingshausen Sea ice. Annals of Glaciology, 52, 271-278, 10.3189/172756411795931651.

Li, L. J., and Coauthors, 2013: The flexible global ocean-atmosphere-land system model, Grid-point Version 2: FGOALS-g2. Adv Atmos Sci, 30, 543-560, Doi 10.1007/S00376-012-2140-6.

Li, X. C., D. M. Holland, E. P. Gerber, and C. Yoo, 2014: Impacts of the north and tropical Atlantic Ocean on the Antarctic Peninsula and sea ice. Nature, 505, 538+ , Doi 10.1038/Nature12945.

Liu, A. K., and E. Mollo-Christensen, 1988: Wave-Propagation in a Solid Ice Pack. J Phys Oceanogr, 18, 1702-1712, Doi 10.1175/1520-

0485(1988)018<1702:Wpiasi>2.0.Co;2.

Liu, J. P., and J. A. Curry, 2010: Accelerated warming of the Southern Ocean and its impacts on the hydrological cycle and sea ice. P Natl Acad Sci USA, 107, 14987-14992, 10.1073/pnas.1003336107.

Liu, J. P., J. A. Curry, and D. G. Martinson, 2004: Interpretation of recent Antarctic sea ice variability. Geophysical Research Letters, 31, Artn L02205

Doi 10.1029/2003gl018732. 
Lubin, D., and R. Massom, 2006: Sea ice. Polar Remote Sensing Volume 1: Atmosphere and Oceans, Springer, 309-728.

Lytle, V. I., and S. F. Ackley, 2001: Snow-ice growth: a fresh-water flux inhibiting deep convection in the Weddell Sea, Antarctica. Ann Glaciol, 33, 45-50, Doi $10.3189 / 172756401781818752$.

Mahlstein, I., P. R. Gent, and S. Solomon, 2013: Historical Antarctic mean sea ice area, sea ice trends, and winds in CMIP5 simulations. J Geophys Res-Atmos, 118, 5105-5110, 10.1002/jgrd.50443.

Maksym, T., and T. Markus, 2008: Antarctic sea ice thickness and snow-to-ice conversion from atmospheric reanalysis and passive microwave snow depth. Journal of Geophysical Research-Oceans, 113, Artn C02s12 10.1029/2006jc004085.

Maksym, T., S. E. Stammerjohn, S. Ackley, and R. Massom, 2012: Antarctic Sea IceA Polar Opposite? Oceanography, 25, 140-151.

Marshall, G. J., 2003: Trends in the southern annular mode from observations and reanalyses. Journal of Climate, 16, 4134-4143, Doi 10.1175/15200442(2003)016<4134:Titsam>2.0.Co;2.

Marshall, G. J., P. A. Stott, J. Turner, W. M. Connolley, J. C. King, and T. A. LachlanCope, 2004: Causes of exceptional atmospheric circulation changes in the Southern Hemisphere. Geophysical Research Letters, 31, Artn L14205 $10.1029 / 2004 \mathrm{gl019952.}$

Marshall, J., and K. Speer, 2012: Closure of the meridional overturning circulation through Southern Ocean upwelling. Nat Geosci, 5, 171-180, 10.1038/NGE01391.

Marshall, J., J. R. Scott, K. C. Armour, J. M. Campin, M. Kelley, and A. Romanou, 2015: The ocean's role in the transient response of climate to abrupt greenhouse gas forcing. Clim Dynam, 44, 2287-2299, 10.1007/s00382-014-2308-0.

Marshall, J., and Coauthors, 2014: The ocean's role in polar climate change: asymmetric Arctic and Antarctic responses to greenhouse gas and ozone forcing. Philosophical transactions. Series A, Mathematical, physical, and engineering sciences, 372, 20130040, 10.1098/rsta.2013.0040.

Marsland, S. J., and J. O. Wolff, 2001: On the sensitivity of Southern Ocean sea ice to the surface freshwater flux: A model study. Journal of Geophysical ResearchOceans, 106, 2723-2741, Doi 10.1029/2000jc900086.

Martin, G. M., and Coauthors, 2011: The HadGEM2 family of Met Office Unified Model climate configurations. Geosci Model Dev, 4, 723-757, Doi 10.5194/Gmd-4723-2011.

Martinson, D., and R. Iannuzzi, 1998: Antarctic ocean-ice interaction: implications from ocean bulk property distributions in the Weddell gyre. 
Antarctic Sea Ice: Physical Processes, Interactions and Variability, M. O. Jeffries, Ed., American Geophysical Union, 243-271.

Martinson, D. G., 1990: Evolution of the Southern-Ocean Winter Mixed Layer and Sea Ice - Open Ocean Deep-Water Formation and Ventilation. Journal of Geophysical Research-Oceans, 95, 11641-11654, 10.1029/Jc095ic07p11641.

Martinson, D. G., and C. Wamser, 1990: Ice Drift and Momentum Exchange in Winter Antarctic Pack Ice. Journal of Geophysical Research-Oceans, 95, 17411755, 10.1029/Jc095ic02p01741.

Martinson, D. G., S. E. Stammerjohn, R. A. Iannuzzi, R. C. Smith, and M. Vernet, 2008: Western Antarctic Peninsula physical oceanography and spatio-temporal variability. Deep-Sea Res Pt Ii, 55, 1964-1987, 10.1016/j.dsr2.2008.04.038.

Massom, R., and S. Stammerjohn, 2010: Antarctic sea ice change and variability Physical and ecological implications. Polar Science, 4, 149-186, 10.1016/j.polar.2010.05.001.

Massom, R., P. Reid, S. Stammerjohn, B. Raymond, A. Fraser, and S. Ushio, 2013: Change and Variability in East Antarctic Sea Ice Seasonality, 1979/80-2009/10. Plos One, 8, ARTN e64756

10.1371/journal.pone.0064756.

Massom, R. A., and Coauthors, 2008: West Antarctic Peninsula sea ice in 2005: Extreme ice compaction and ice edge retreat due to strong anomaly with respect to climate. Journal of Geophysical Research-Oceans, 113, Artn C02s20 10.1029/2007jc004239.

Massom, R. A., and Coauthors, 2010: Examining the interaction between multiyear landfast sea ice and the Mertz Glacier Tongue, East Antarctica: Another factor in ice sheet stability? Journal of Geophysical Research-Oceans, 115, Artn C12027

Doi 10.1029/2009jc006083.

Massom, R. A., and Coauthors, 2006: Extreme anomalous atmospheric circulation in the West Antarctic Peninsula region in Austral Spring and Summer 2001/02, and its profound impact on sea ice and biota. Journal of Climate, 19, 3544-3571, Doi 10.1175/Jcli3805.1.

Massonnet, F., P. Mathiot, T. Fichefet, H. Goosse, C. K. Beatty, M. Vancoppenolle, and T. Lavergne, 2013: A model reconstruction of the Antarctic sea ice thickness and volume changes over 1980-2008 using data assimilation. Ocean Modelling, 64, 67-75, 10.1016/j.ocemod.2013.01.003.

Matear, R. J., T. J. O'kane, J. S. Risbey, and M. A. Chamberlain, 2015: Sources of heterogeneous variability and trends in Antarctic sea-ice. Nat Commun, 6, $10.1038 /$ ncomms 9656 .

McClintock, J., H. Ducklow, and W. Fraser, 2008: Ecological Responses to Climate Change on the Antarctic Peninsula. American Scientist, 96, 10.1511/2008.73.302. 
Meier, W. N., S. J. S. Khalsa, and M. H. Savoie, 2011: Intersensor Calibration Between F-13 SSM/I and F-17 SSMIS Near-Real-Time Sea Ice Estimates. Geoscience and Remote Sensing, IEEE Transactions on, 49, 3343-3349, 10.1109/tgrs.2011.2117433.

Meier, W. N., D. Gallaher, and G. G. Campbell, 2013a: New estimates of Arctic and Antarctic sea ice extent during September 1964 from recovered Nimbus I satellite imagery. Cryosphere, 7, 699-705, Doi 10.5194/Tc-7-699-2013.

Meier, W. N., G. Peng, D. J. Scott, and M. Savoie, 2014: Verification of a new NOAA/NSIDC passive microwave sea-ice concentration climate record. Polar Res, 33, 21004, 10.3402/polar.v33.21004.

Meier, W. N., F. Fetterer, M. Savoie, S. Mallory, R. Duerr, and J. Stroeve, 2013b: NOAA/NSIDC Climate Data Record of Passive Microwave Sea Ice Concentration. 2 ed., N. S. a. I. D. Center, Ed., NSIDC.

Meijers, A. J., 2014: The Southern Ocean in the Coupled Model Intercomparison Project phase 5. Philosophical transactions. Series A, Mathematical, physical, and engineering sciences, 372, 20130296, 10.1098/rsta.2013.0296.

Meredith, M. P., and J. C. King, 2005: Rapid climate change in the ocean west of the Antarctic Peninsula during the second half of the 20th century. Geophysical Research Letters, 32, Artn L19604 $10.1029 / 2005 \mathrm{gl024042.}$

Meredith, M. P., and Coauthors, 2013: The Freshwater System West of the Antarctic Peninsula: Spatial and Temporal Changes. Journal of Climate, 26, 16691684, 10.1175/JCLI-D-12-00246.1.

Meredith, M. P., and Coauthors, 2016: Changing distributions of sea ice melt and meteoric water west of the Antarctic Peninsula. Deep Sea Research Part II: Topical Studies in Oceanography, http://dx.doi.org/10.1016/j.dsr2.2016.04.019.

Mignot, J., and S. Bony, 2013: Presentation and analysis of the IPSL and CNRM climate models used in CMIP5. Clim Dynam, 40, 2089-2089, Doi 10.1007/S00382-013-1720-1.

Mo, K. C., 2000: Relationships between low-frequency variability in the Southern Hemisphere and sea surface temperature anomalies. Journal of Climate, 13, 3599-3610, 10.1175/1520-0442(2000)013<3599:Rblfvi>2.0.Co;2.

Mo, K. C., and R. W. Higgins, 1998: The Pacific-South American modes and tropical convection during the Southern Hemisphere winter. Mon Weather Rev, 126, 1581-1596, Doi 10.1175/1520-0493(1998)126<1581:Tpsama>2.0.Co;2.

Mo, K. C., and J. N. Paegle, 2001: The Pacific-South American modes and their downstream effects. Int J Climatol, 21, 1211-1229, Doi 10.1002/Joc.685. 
Monselesan, D., T. J. O'Kane, J. S. Risbey, and J. A. Church, 2015: Internal climate memory in observations and models. Geophysical Research Letters, 10.1002/2014GL062765.

Morrison, A. K., T. L. Frolicher, and J. L. Sarmiento, 2015: Upwelling in the SOUTHERN OCEAN. Phys Today, 68, 27-32.

Murphy, E. J., A. Clarke, C. Symon, and J. Priddle, 1995: Temporal Variation in Antarctic Sea-Ice - Analysis of a Long-Term Fast-Ice Record from the SouthOrkney Islands. Deep-Sea Res Pt I, 42, 1045-1062, Doi 10.1016/09670637(95)00057-D.

Murphy, E. J., A. Clarke, N. J. Abram, and J. Turner, 2014: Variability of sea-ice in the northern Weddell Sea during the 20th century. Journal of Geophysical Research: Oceans, 119, 4549-4572, 10.1002/2013jc009511.

Nghiem, S. V., I. G. Rigor, P. Clemente-Colón, G. Neumann, and P. P. Li, 2016: Geophysical constraints on the Antarctic sea ice cover. Remote Sens Environ, 181, 281-292, 10.1016/j.rse.2016.04.005.

Nicolas, J. P., and D. H. Bromwich, 2014: New Reconstruction of Antarctic NearSurface Temperatures: Multidecadal Trends and Reliability of Global Reanalyses. Journal of Climate, 27, 8070-8093, 10.1175/JCLI-D-13-00733.1.

O’Kane, T. J., R. J. Matear, M. A. Chamberlain, J. S. Risbey, B. M. Sloyan, and I. Horenko, 2013: Decadal variability in an OGCM Southern Ocean: Intrinsic modes, forced modes and metastable states. Ocean Modelling, 69, 1-21, 10.1016/j.ocemod.2013.04.009.

Ohshima, K. I., and Coauthors, 2013: Antarctic BottomWater production by intense sea-ice formation in the Cape Darnley polynya. Nat Geosci, 6, 235-240, Doi 10.1038/Ngeo1738.

Okumura, Y. M., D. Schneider, C. Deser, and R. Wilson, 2012: DecadalInterdecadal Climate Variability over Antarctica and Linkages to the Tropics: Analysis of Ice Core, Instrumental, and Tropical Proxy Data. Journal of Climate, 25, 7421-7441, Doi 10.1175/Jcli-D-12-00050.1.

Orsi, A. H., G. C. Johnson, and J. L. Bullister, 1999: Circulation, mixing, and production of Antarctic Bottom Water. Prog Oceanogr, 43, 55-109, Doi 10.1016/S0079-6611(99)00004-X.

Park, Y. H., F. Roquet, and F. Vivier, 2004: Quasi-stationary ENSO wave signals versus the Antarctic Circumpolar Wave scenario. Geophysical Research Letters, 31, Artn L09315 10.1029/2004gl019806.

Parkinson, C. L., 1994: Spatial Patterns in the Length of the Sea-Ice Season in the Southern-Ocean, 1979-1986. Journal of Geophysical Research-Oceans, 99, 1632716339, Doi 10.1029/94jc01146. 
- - 2002: Trends in the length of the Southern Ocean sea-ice season, 1979-99. Ann Glaciol, 34, 435-440, Doi 10.3189/172756402781817482.

Parkinson, C. L., and D. J. Cavalieri, 2012: Antarctic sea ice variability and trends, 1979-2010. Cryosphere, 6, 871-880, Doi 10.5194/Tc-6-871-2012.

Parkinson, C. L., J. C. Comiso, and H. J. Zwally, 1999: Nimbus-5 ESMR Polar Gridded Sea Ice Concentrations. National Snow and Ice Data Center.

Pauling, A. G., C. M. Bitz, I. J. Smith, and P. J. Langhorne, 2016: The Response of the Southern Ocean and Antarctic Sea Ice to Freshwater from Ice Shelves in an Earth System Model. Journal of Climate, 29, 1655-1672, 10.1175/JCLI-D-15-0501.1.

Peng, G., W. N. Meier, D. J. Scott, and M. H. Savoie, 2013: A long-term and reproducible passive microwave sea ice concentration data record for climate studies and monitoring. Earth Syst. Sci. Data, 5, 311-318, 10.5194/essd-5-3112013.

Polvani, L. M., and K. L. Smith, 2013: Can natural variability explain observed Antarctic sea ice trends? New modeling evidence from CMIP5. Geophysical Research Letters, 40, 3195-3199, 10.1002/grl.50578.

Powell, D. C., T. Markus, and A. Stossel, 2005: Effects of snow depth forcing on Southern Ocean sea ice simulations. Journal of Geophysical Research-Oceans, 110, Artn C06001 10.1029/2003jc002212.

Purkey, S. G., and G. C. Johnson, 2013: Antarctic Bottom Water Warming and Freshening: Contributions to Sea Level Rise, Ocean Freshwater Budgets, and Global Heat Gain. Journal of Climate, 26, 6105-6122, Doi 10.1175/Jcli-D-1200834.1.

Randall-Goodwin, E., and Coauthors, 2015: Freshwater distributions and water mass structure in the Amundsen Sea Polynya region, Antarctica. Elemanta: Science of the Anthropocene, 3, 000065, 10.12952/journal.elementa.000065.

Raphael, M. N., 2007: The influence of atmospheric zonal wave three on Antarctic sea ice variability. J Geophys Res-Atmos, 112, Artn D12112 10.1029/2006jd007852.

Raphael, M. N., and W. Hobbs, 2014: The influence of the large-scale atmospheric circulation on Antarctic sea ice during ice advance and retreat seasons. Geophysical Research Letters, 41, 5037-5045, 10.1002/2014gl060365.

Raphael, M. N., W. Hobbs, and I. Wainer, 2011: The effect of Antarctic sea ice on the Southern Hemisphere atmosphere during the southern summer. Clim Dynam, 36, 1403-1417, Doi 10.1007/S00382-010-0892-1.

Raphael, M. N., and Coauthors, 2016: The Amundsen Sea Low: Variability, Change, and Impact on Antarctic Climate. B Am Meteorol Soc, 97, 111-121, 10.1175/bams-d-14-00018.1. 
Reid, P., S. Stammerjohn, R. Massom, T. A. Scambos, and J. Lieser, 2015: The record 2013 Southern Hemisphere sea-ice extent maximum. Annals of Glaciology, 56, 99-106, 10.3189/2015AoG69A892.

Riser, S. C., and Coauthors, 2016: Fifteen years of ocean observations with the global Argo array. Nature Climate Change, 6, 145-153, 10.1038/NCLIMATE2872.

Ropelewski, C. F., 1990: NOAA/NMC/CAC Arctic and Antarctic monthly sea ice extent, 1973-1990. 1 ed., National Snow and Ice Data Center.

Roquet, F., and Coauthors, 2014: A Southern Indian Ocean database of hydrographic profiles obtained with instrumented elephant seals. Scientific Data, 1, 140028, 10.1038/sdata.2014.28.

Ross, R. M., L. B. Quetin, D. G. Martinson, R. A. Iannuzzi, S. E. Stammerjohn, and R. C. Smith, 2008: Palmer LTER: Patterns of distribution of five dominant zooplankton species in the epipelagic zone west of the Antarctic Peninsula, 19932004. Deep-Sea Res Pt Ii, 55, 2086-2105, 10.1016/j.dsr2.2008.04.037.

Rye, C. D., and Coauthors, 2014: Rapid sea-level rise along the Antarctic margins in response to increased glacial discharge. Nat Geosci, 7, 732-735, 10.1038/NGE02230.

Saba, G. K., and Coauthors, 2014: Winter and spring controls on the summer food web of the coastal West Antarctic Peninsula. Nat Commun, 5, Artn 4318 10.1038/Ncomms5318.

Saha, S., and Coauthors, 2010: The Ncep Climate Forecast System Reanalysis. $B$ Am Meteorol Soc, 91, 1015-1057, 10.1175/2010BAMS3001.1.

Sallee, J. B., E. Shuckburgh, N. Bruneau, A. J. S. Meijers, T. J. Bracegirdle, and Z. Wang, 2013: Assessment of Southern Ocean mixed-layer depths in CMIP5 models: Historical bias and forcing response. Journal of Geophysical ResearchOceans, 118, 1845-1862, Doi 10.1002/Jgrc.20157.

Scambos, T. A., J. A. Bohlander, C. A. Shuman, and P. Skvarca, 2004: Glacier acceleration and thinning after ice shelf collapse in the Larsen B embayment, Antarctica. Geophysical Research Letters, 31, Artn L18402

Doi 10.1029/2004gl020670.

Schmidtko, S., K. J. Heywood, A. F. Thompson, and S. Aoki, 2014: Multidecadal warming of Antarctic waters. Science, 346, 1227-1231, 10.1126/science.1256117.

Schneider, D. P., and E. J. Steig, 2008: Ice cores record significant 1940s Antarctic warmth related to tropical climate variability. P Natl Acad Sci USA, 105, 1215412158, 10.1073/pnas.0803627105.

Screen, J. A., 2011: Sudden increase in Antarctic sea ice: Fact or artifact? Geophysical Research Letters, 38, L13702, Artn L13702

Doi 10.1029/2011gl047553. 
Sen Gupta, A., and M. H. England, 2006: Coupled ocean-atmosphere-ice response to variations in the Southern Annular Mode. Journal of Climate, 19, 4457-4486, Doi 10.1175/Jcli3843.1.

Shu, Q., Z. Song, and F. Qiao, 2015: Assessment of sea ice simulations in the CMIP5 models. The Cryosphere, 9, 399-409, 10.5194/tc-9-399-2015.

Sigmond, M., and J. C. Fyfe, 2010: Has the ozone hole contributed to increased Antarctic sea ice extent? Geophysical Research Letters, 37, n/a-n/a, 10.1029/2010gl044301.

Simmonds, I., 2015: Comparing and contrasting the behaviour of Arctic and Antarctic sea ice over the 35 year period 1979-2013. Annals of Glaciology, 56, 1828, 10.3189/2015AoG69A909.

Simmonds, I., and T. H. Jacka, 1995: Relationships between the Interannual Variability of Antarctic Sea-Ice and the Southern Oscillation. Journal of Climate, 8, 637-647, Doi 10.1175/1520-0442(1995)008<0637:Rbtivo>2.0.Co;2.

Simmonds, I., K. Keay, and E. P. Lim, 2003: Synoptic activity in the seas around Antarctica. Mon Weather Rev, 131, 272-288, Doi 10.1175/15200493(2003)131<0272:Saitsa>2.0.Co;2.

Simpkins, G. R., L. M. Ciasto, and M. H. England, 2013: Observed variations in multidecadal Antarctic sea ice trends during 1979-2012. Geophysical Research Letters, 40, 3643-3648, Doi 10.1002/Grl.50715.

Simpkins, G. R., L. M. Ciasto, D. W. J. Thompson, and M. H. England, 2012:

Seasonal Relationships between Large-Scale Climate Variability and Antarctic Sea Ice Concentration. Journal of Climate, 25, 5451-5469, Doi 10.1175/Jcli-D-1100367.1.

Simpkins, G. R., S. McGregor, A. S. Taschetto, L. M. Ciasto, and M. H. England, 2014: Tropical Connections to Climatic Change in the Extratropical Southern Hemisphere: The Role of Atlantic SST Trends. Journal of Climate, 27, 4923-4936, Doi 10.1175/Jcli-D-13-00615.1.

Sinclair, K. E., N. A. N. Bertler, M. M. Bowen, and K. R. Arrigo, 2014: Twentieth century sea-ice trends in the Ross Sea from a high-resolution, coastal ice-core record. Geophysical Research Letters, 41, 10.1002/2014GL059821.

St-Laurent, P., J. M. Klinck, and M. S. Dinniman, 2015: Impact of local winter cooling on the melt of Pine Island Glacier, Antarctica. Journal of Geophysical Research: Oceans, 120, 10.1002/2015JC010709.

Stammerjohn, S., R. Massom, D. Rind, and D. Martinson, 2012: Regions of rapid sea ice change: An inter-hemispheric seasonal comparison. Geophysical Research Letters, 39, 10.1029/2012gl050874. 
Stammerjohn, S., and Coauthors, 2015: Seasonal sea ice changes in the Amundsen Sea, Antarctica, over the period of 1979-2014. Elemanta: Science of the Anthropocene, 3, 000055, 10.12952/journal.elementa.000055.

Stammerjohn, S. E., D. G. Martinson, R. C. Smith, X. Yuan, and D. Rind, 2008: Trends in Antarctic annual sea ice retreat and advance and their relation to El Niño-Southern Oscillation and Southern Annular Mode variability. Journal of Geophysical Research, 113, C03S90, 10.1029/2007jc004269.

Steig, E. J., Q. Ding, D. S. Battisti, and A. Jenkins, 2012: Tropical forcing of Circumpolar Deep Water Inflow and outlet glacier thinning in the Amundsen Sea Embayment, West Antarctica. Annals of Glaciology, 53, 19-28, 10.3189/2012AoG60A110.

Steig, E. J., and Coauthors, 2013: Recent climate and ice-sheet changes in West Antarctica compared with the past 2,000 years. Nat Geosci, 6, 372-375, 10.1038/NGE01778.

Steinberg, D. K., and Coauthors, 2015: Long-term (1993-2013) changes in macrozooplankton off the Western Antarctic Peninsula. Deep-Sea Res Pt I, 101, 54-70, 10.1016/j.dsr.2015.02.009.

Sterl, A., G. J. van Oldenborgh, W. Hazeleger, and G. Burgers, 2007: On the robustness of ENSO teleconnections. Clim Dynam, 29, 469-485, 10.1007/s00382007-0251-z.

Stossel, A., Z. R. Zhang, and T. Vihma, 2011: The effect of alternative real-time wind forcing on Southern Ocean sea ice simulations. Journal of Geophysical Research-Oceans, 116, Artn C11021

Doi 10.1029/2011jc007328.

Stroeve, J. C., S. Jenouvrier, G. G. Campbell, C. Barbraud, and K. Delord, 2016: Mapping and Assessing Variability in the Antarctic Marginal Ice Zone, the Pack Ice and Coastal Polynyas. The Cryosphere Discussions, in review, 10.5194/tc2016-26.

Sturm, M., and R. Massom, 2009: Snow and Sea Ice. Sea Ice, 2 ed., D. N. Thomas, and G. S. Dieckmann, Eds., Wiley-Blackwell.

Swart, N. C., and J. C. Fyfe, 2013: The influence of recent Antarctic ice sheet retreat on simulated sea ice area trends. Geophysical Research Letters, 40, 43284332, Doi 10.1002/Grl.50820.

Taylor, K. E., R. J. Stouffer, and G. A. Meehl, 2012: An Overview of Cmip5 and the Experiment Design. B Am Meteorol Soc, 93, 485-498, Doi 10.1175/Bams-D-1100094.1.

Thoma, M., A. Jenkins, D. Holland, and S. Jacobs, 2008: Modelling Circumpolar Deep Water intrusions on the Amundsen Sea continental shelf, Antarctica. Geophysical Research Letters, 35, Artn L18602 10.1029/2008gl034939. 
Thomas, D. N., and G. S. Dieckmann, 2009: Sea ice. 2nd ed. Wiley-Blackwell, 638 pp.

Thomas, E. R., and N. J. Abram, 2016: Ice core reconstruction of sea ice change in the Amundsen-Ross Seas since 1702 AD. Geophysical Research Letters, Accepted articles, 10.1002/2016GL068130.

Thompson, D. W. J., and J. M. Wallace, 2000: Annular modes in the extratropical circulation. Part I: Month-to-month variability. Journal of Climate, 13, 1000-1016, Doi 10.1175/1520-0442(2000)013<1000:Amitec>2.0.Co;2.

Thompson, D. W. J., and S. Solomon, 2002: Interpretation of recent Southern Hemisphere climate change. Science, 296, 895-899, Doi 10.1126/Science.1069270.

Thompson, D. W. J., J. M. Wallace, and G. C. Hegerl, 2000: Annular modes in the extratropical circulation. Part II: Trends. Journal of Climate, 13, 1018-1036, Doi 10.1175/1520-0442(2000)013<1018:Amitec>2.0.Co;2.

Titchner, H. A., and N. A. Rayner, 2014: The Met Office Hadley Centre sea ice and sea surface temperature data set, version 2: 1 . Sea ice concentrations. J Geophys Res-Atmos, 119, 2864-2889, 10.1002/2013JD020316.

Turner, J., 2004: The El Nino-southern oscillation and Antarctica. Int J Climatol, 24, 1-31, 10.1002/joc.965.

Turner, J., J. S. Hosking, T. Phillips, and G. J. Marshall, 2013a: Temporal and spatial evolution of the Antarctic sea ice prior to the September 2012 record maximum extent. Geophysical Research Letters, 40, 5894-5898, 10.1002/2013GL058371.

Turner, J., T. Maksym, T. Phillips, G. J. Marshall, and M. P. Meredith, 2013b: The impact of changes in sea ice advance on the large winter warming on the western Antarctic Peninsula. Int J Climatol, 33, 852-861, 10.1002/joc.3474.

Turner, J., T. Phillips, J. S. Hosking, G. J. Marshall, and A. Orr, 2013c: The Amundsen Sea low. Int J Climatol, 33, 1818-1829, 10.1002/joc.3558.

Turner, J., T. J. Bracegirdle, T. Phillips, G. J. Marshall, and J. S. Hosking, 2013d: An Initial Assessment of Antarctic Sea Ice Extent in the CMIP5 Models. Journal of Climate, 26, 1473-1484, Doi 10.1175/Jcli-D-12-00068.1.

Turner, J., J. S. Hosking, T. J. Bracegirdle, G. J. Marshall, and T. Phillips, 2015a: Recent changes in Antarctic Sea Ice. Philos T R Soc A, 373, Artn 20140163 10.1098/Rsta.2014.0163.

Turner, J., J. S. Hosking, G. J. Marshall, T. Phillips, and T. J. Bracegirdle, 2015b: Antarctic sea ice increase consistent with intrinsic variability of the Amundsen Sea Low. Clim Dynam, 10.1007/s00382-015-2708-9. 
Uotila, P., P. R. Holland, T. Vihma, S. J. Marsland, and N. Kimura, 2014: Is realistic Antarctic sea-ice extent in climate models the result of excessive ice drift? Ocean Modelling, 79, 33-42, Doi 10.1016/J.Ocemod.2014.04.004.

van Wijk, E. M., and S. R. Rintoul, 2014: Freshening drives contraction of Antarctic Bottom Water in the Australian Antarctic Basin. Geophysical Research Letters, 41, 1657-1664, 10.1002/2013gl058921.

Vaughan, D. G., and Coauthors, 2013: Observations: Cryosphere. Climate Change 2013: The Physical Science Basis. Contribution of Working Group I to the Fifth Assessment Report of the Intergovernmental Panel on Climate Change, T. F. Stocker, and Coauthors, Eds.

Venables, H. J., and M. P. Meredith, 2014: Feedbacks between ice cover, ocean stratification, and heat content in Ryder Bay, western Antarctic Peninsula. Journal of Geophysical Research-Oceans, 119, 5323-5336, 10.1002/2013JC009669.

von Storch, H., E. Zorita, J. M. Jones, Y. Dimitriev, F. Gonzalez-Rouco, and S. F. B. Tett, 2004: Reconstructing past climate from noisy data. Science, 306, 679-682, 10.1126/science.1096109.

Watanabe, M., and Coauthors, 2010: Improved Climate Simulation by MIROC5. Mean States, Variability, and Climate Sensitivity. J Climate, 23, 6312-6335, Doi 10.1175/2010jcli3679.1.

Watanabe, S., and Coauthors, 2011: MIROC-ESM 2010: model description and basic results of CMIP5-20c3m experiments. Geosci Model Dev, 4, 845-872, Doi 10.5194/Gmd-4-845-2011.

Watkins, A. B., and I. Simmonds, 1999: A late spring surge in the open water of the Antarctic sea ice pack. Geophysical Research Letters, 26, 1481-1484, Doi 10.1029/1999gl900292.

Weatherly, J. W., 2004: Sensitivity of Antarctic precipitation to sea ice concentrations in a general circulation model. Journal of Climate, 17, 3214-3223, Doi 10.1175/1520-0442(2004)017<3214:Soapts>2.0.Co;2.

Weeks, W. F., 2010: On Sea Ice. University of Alaska Press, 664 pp.

White, W. B., and R. G. Peterson, 1996: An Antarctic circumpolar wave in surface pressure, wind, temperature and sea-ice extent. Nature, 380, 699-702, Doi 10.1038/380699a0.

Williams, G., T. Maksym, J. Wilkinson, C. Kunz, C. Murphy, P. Kimball, and H. Singh, 2015: Thick and deformed Antarctic sea ice mapped with autonomous underwater vehicles. Nat Geosci, 8, 61-67, 10.1038/NGEO2299.

Wong, A. P. S., and S. C. Riser, 2011: Profiling Float Observations of the Upper Ocean under Sea Ice off the Wilkes Land Coast of Antarctica. J Phys Oceanogr, 41, 1102-1115, 10.1175/2011JP04516.1. 
Worby, A. P., and J. C. Comiso, 2004: Studies of the Antarctic sea ice edge and ice extent from satellite and ship observations. Remote Sens Environ, 92, 98-111, 10.1016/j.rse.2004.05.007.

Worby, A. P., T. Markus, A. D. Steer, V. I. Lytle, and R. A. Massom, 2008a: Evaluation of AMSR-E snow depth product over East Antarctic sea ice using in situ measurements and aerial photography. Journal of Geophysical ResearchOceans, 113, Artn C05s94 10.1029/2007jc004181.

Worby, A. P., C. A. Geiger, M. J. Paget, M. L. Van Woert, S. F. Ackley, and T. L. DeLiberty, 2008b: Thickness distribution of Antarctic sea ice. Journal of Geophysical Research-Oceans, 113, Artn C05s92 10.1029/2007jc004254.

Xiao-Ge, X., W. Tong-Wen, and Z. Jie, 2013: Introduction of CMIP5 Experiments Carried out with the Climate System Models of Beijing Climate Center. Advances in Climate Change Research, 4, 41-49, 10.3724/SP.J.1248.2013.041.

Xie, H. J., A. E. Tekeli, S. F. Ackley, D. H. Yi, and H. J. Zwally, 2013: Sea ice thickness estimations from ICESat Altimetry over the Bellingshausen and Amundsen Seas, 2003-2009. Journal of Geophysical Research-Oceans, 118, 2438-2453, Doi 10.1002/Jgrc.20179.

Yang, D., and O. A. Saenko, 2012: Ocean Heat Transport and Its Projected Change in CanESM2. J Climate, 25, 8148-8163, Doi 10.1175/Jcli-D-11-00715.1.

Yu, L. J., and Coauthors, 2011: Interpretation of recent trends in Antarctic sea ice concentration. J Appl Remote Sens, 5, Artn 053557

10.1117/1.3643691.

Yuan, X. J., 2004: ENSO-related impacts on Antarctic sea ice: a synthesis of phenomenon and mechanisms. Antarct Sci, 16, 415-425,

$10.1017 /$ S0954102004002238.

Yuan, X. J., and C. H. Li, 2008: Climate modes in southern high latitudes and their impacts on Antarctic sea ice. Journal of Geophysical Research-Oceans, 113, Artn C06s91

10.1029/2006jc004067.

Yukimoto, S., and Coauthors, 2012: A New Global Climate Model of the Meteorological Research Institute: MRI-CGCM3-Model Description and Basic Performance. J Meteorol Soc Jpn, 90A, 23-64, Doi 10.2151/Jmsj.2012-A02.

Zhang, J. L., 2007: Increasing Antarctic sea ice under warming atmospheric and oceanic conditions. Journal of Climate, 20, 2515-2529, Doi 10.1175/Jcli4136.1.

- - 2014: Modeling the Impact of Wind Intensification on Antarctic Sea Ice Volume. Journal of Climate, 27, 202-214, Doi 10.1175/Jcli-D-12-00139.1. 
Zunz, V., and H. Goosse, 2015: Influence of freshwater input on the skill of decadal forecast of sea ice in the Southern Ocean. The Cryosphere, 9, 541-556, 10.5194/tc-9-541-2015.

Zunz, V., H. Goosse, and F. Massonnet, 2013: How does internal variability influence the ability of CMIP5 models to reproduce the recent trend in Southern Ocean sea ice extent? The Cryosphere, 7, 451-468, 10.5194/tc-7-451-2013.

Zwally, H. J., J. C. Comiso, C. L. Parkinson, D. J. Cavalieri, and P. Gloersen, 2002: Variability of Antarctic sea ice 1979-1998. Journal of Geophysical ResearchOceans, 107, Artn 3041

Doi 10.1029/2000jc000733. 